\title{
International Conference on Genetic Variation, Nutrition and Physical Activity
}

May 22-24, 2003, S. Margherita di Pula, Cagliari, Italy

Chair Persons:

S. Muntoni (Cagliari); A.P. Simopoulos (Washington, D.C.)

\section{Abstracts}

Guest Editor

Sergio Muntoni, Cagliari 


\section{Nutrition\& Metabolism}

\section{Genetics: Nutritional Implications}

\author{
Artemis P. Simopoulos \\ The Center for Genetics, Nutrition and Health, \\ Washington, D.C., USA
}

Using the tools of molecular biology and genetics, research is defining the mechanisms by which genes influence nutrient absorption, metabolism and excretion, taste perception, and degree of satiation; and the mechanisms by which nutrients influence gene expression. Furthermore, advances in molecular and recombinant DNA technology have led to exquisite studies in the field of genetics and the recognition in a much more specific way, through DNA sequencing, how unique each one of us is, and the extent to which genetic variation occurs in human beings. How extensive genetic variation is depends on how it is measured. At the level of DNA it is considerable since every 100-250 nucleotides there is a substitution leading to single nucleotide polymorphisms or SNPs. Today 3 million SNPs have been identified in the human genome by the International SNP Map Working Group and their number is increasing daily. The main use of the human SNP map will be in dissecting the contributions of individual genes to diseases that have a complex, multigene basis. Knowledge of genetic variation already affects patient care to some degree. For example, gene variants lead to tissue and organ incompatibility, affecting the success of transplants. The importance of the effects of genetic variation has been extensively studied and applied by pharmacologists in drug development and evaluation of drug metabolism and adverse reactions to drugs. In the past two decades, physicians, geneticists and nutritionists began to study the effects of genetic variation, and gene-nutrient interactions in the management of chronic diseases.

Coronary artery disease, hypertension, diabetes, cancer and other chronic diseases in adults tend to aggregate in families, and the risk of relatives is much higher than that in the general population. Because families share both genes and environment, similarity may result from either. Much research has been carried out to define the contribution of each, and their interaction in the development of the individual. Broadly defined, heritability is the proportion of the total variance that can be explained by genes. Studies in the United States have shown that $50 \%$ of the variance in plasma cholesterol concentration is genetically determined. Mongeau determined that $30-60 \%$ of the variance in blood pressure is genetically determined; between 15 and $50 \%$ of the variance in fibrinogen, an independent risk factor for coronary artery disease, is genetically determined. Fifteen percent of the variance was found in the United Kingdom, while $50 \%$ is the figure among the Swedish population, indicating significant differences between populations. Morrison et al. in Australia showed that $75 \%$ of the variance in bone density is genetically determined. Calculations of heritability are relevant only to the specific population and environment from which information is gathered. Heritability may vary between populations if they differ in the prevalence of the types of genes affecting the disease entity under consideration.
It is estimated that in 5-10 years the pace of discovery of single nucleotide polymorphisms and the developments in high throughput genotyping should lead to the identification of many susceptibility genes for complex disorders. Genotyping will become part of the routine management of an expanding range of human diseases over the next 10 years and nutrigenomics will supplement pharmacogenetics. Knowing who is at risk would be useful if it meant that one could avoid the environmental triggers that convert susceptibility into disease.

How will genetics and nutrigenetics look in the future? Genetics will not remain the exclusive prerogative of regional genetic centers. Instead, every physician will need to use genetic knowledge and combine it with appropriate dietary regimen, type and amount of physical activity, and, if needed, drugs. For common adult onset conditions such as diabetes and circulatory disorders the interaction between genes and the environment is starting to be understood and there is great interest in the potential for DNA diagnostics.

The new genetics has enormous implications for nutrition research both in the prevention and management of chronic diseases. The new millennium is a remarkable time for Medicine and Nutrition when the potential for improving human health is unequalled in history. With the unfolding genomic and technological revolution, continuing investments in research offers unprecedented opportunities to understand disease processes, prevent intrinsic and environmental risks to health and develop new approaches to improve the quality of life worldwide. Although the emphasis of new genetics has been on pharmacogenetics, it is the responsibility of the geneticists and nutrition scientists to expand in parallel the relationship of genetics and nutrition and establish nutrigenetics/nutrigenomics as a major discipline in nutrition in the 21 st century.

In the future, the focus will shift to prevention. It will be easier, indeed routine, to identify genetic predispositions in family members at risk, and probably those at risk in the population at large. As a consequence, it will be necessary to educate people at risk to the advantages of maintaining healthy life styles, avoiding risk, and seeking out preventive therapies. Furthermore, knowledge of genetic susceptibility to disease will help identify those at higher risk for disease, as well as their response to diet.

Because the same genotype may not confer the same risk in all populations, populations should not copy each other's dietary recommendations for the prevention of coronary artery disease, and cancer, or any other disease for that matter.

The prospect of targeting specific dietary treatment to those predicted to gain the most therapeutic benefit clearly has important clinical and economic consequences, particularly in diseases of high prevalence such as coronary artery disease, hypertension, diabetes, osteoporosis, and possibly cancer.

There is no single universal approach for what we are calling the 'life-style' approach to diseases with genetic predisposition. The approach will have to vary with national dietary patterns and national economy. Therefore, it will be necessary to promote life-style patterns that will be compatible with a healthier phenotypic expression of genotypes evolved under different conditions, which means individualized prescriptions and gene-based designer diets.

\begin{tabular}{ll}
\hline KARGER & (c) 2003 S. Karger AG, Basel \\
0250-6807/03/0475-0230\$19.50 \\
$\begin{array}{l}\text { Fax +4161306 1234 } \\
\begin{array}{l}\text { E-Mail karger@karger.ch } \\
\text { www.karger.com }\end{array}\end{array}$ & $\begin{array}{l}\text { Accessible online at: } \\
\text { www.karger.com/anm }\end{array}$
\end{tabular}




\section{Bibliography}

Mongeau J-G: Heredity and blood pressure. Semin Nephrol 1989;9:208-216. Morrison NA, Qi JC, Tokita A, Kelly PJ, Crofts L, Nguyen TW, Sambrook PN, Eisman JA: Prediction of bone density from vitamin D receptor alleles. Nature 1994;367:284-287.

Simopoulos AP: The role of fatty acids in gene expression: Health implications. Ann Nutr Metab 1996;40:303-311.

Simopoulos AP: Evolutionary aspects of nutrition and health: Diet, exercise, genetics and chronic disease. World Rev Nutr Diet, Basel, Karger, 1999, vol. 84 .

Simopoulos AP: Genetic variation and dietary response:Nutrigenetics/nutrigenomics. Asian Pacific J Clin Nutr 2002;11(S6):S117-S128.

Simopoulos AP, Childs B: Committee for the Study of Inborn Errors of Metabolism, Division of Medical Sciences, Assembly of Life Sciences, National Research Council. Genetic Screening. Programs, Principles and Research. Washington, D.C., National Academy of Sciences, 1975.

Simopoulos AP, Childs B (eds): Genetic variation and nutrition. World Rev Nutr Diet, Basel, Karger, 1990, vol. 63.

Simopoulos AP, Herbert V, Jacobson B: The healing diet. New York, Macmillan, 1995.

Simopoulos AP, Nestel PJ (eds): Genetic variation and dietary response. World Rev Nutr Diet, Basel, Karger, 1997, vol. 80.

Simopoulos AP, Pavlou KN (eds): Nutrition and fitness 1: Diet, genes, physical activity and health. World Rev Nutr Diet, Basel, Karger, 2001, vol. 89.

\section{The European Union Project on Genetics, Nutrition and CHD - The IMMIDIET Project (2001-2004)}

\author{
Michel de Lorgeril', Licia lacoviello ${ }^{2}$ \\ ${ }^{1}$ LSCPA, Université Joseph Fourier de Grenoble, France; \\ 2'Angela Valenti' Laboratory of Genetic and Environmental \\ Risk Factors for Thrombotic Diseases, CMNS, \\ Santa Maria Imbaro, Italy
}

The main aims of the IMMIDIET study were to evaluate (1) the present dietary and the risk profile of three European communities at different risk of coronary heart disease (CHD) and (2) the impact of migration on risk factors for CHD.

Because genetic factors have also been implicated in the development of CHD (genes indeed continuously interact with environmental factors in determining the pathogenesis of CHD), genetic polymorphisms were also evaluated.

Dietary habits and genetic polymorphisms are evaluated in an Italian, Belgian and English population sample. The historical Italian migration to Belgium and the integration through mixed marriage are considered as a model of gene-environment interaction. As an index of CHD risk factor profile, factors that are most likely under the combined influence of both dietary and genetic determinants are investigated. A multilanguage integrated food-frequency questionnaire has been specifically developed for that study. To evaluate, the real effect of nutrition on CHD risk, biomarkers of food intake are also studied. In particular, plasma and red cell membrane fatty acids are evaluated and preliminary data will be presented.

An important issue is that the Project has been designed to have a direct educational impact on health care providers and general population. Indeed, the project will include healthy adult populations (nuclear couples) recruited through the collaboration of general practitioners (GPs). GPs are indeed key persons through whom primary prevention can be implemented successfully, since they can give

International Conference on Genetic

Ann Nutr Metab 2003;47:229-254 231 integrated and personalised advices by translating scientific knowledge in an understandable way.

In that conference, after giving some generalities about IMMIDIET, we will focus the report on the fatty acid question and we will comment some preliminary data.

Table 1: Red cell fatty acids

\begin{tabular}{llll}
\hline & Belgium & UK & Italy \\
\hline Total fatty acids & 3,986 & 3,703 & 3,962 \\
Saturated (\%) & 37.5 & 38.4 & 37.1 \\
Total MUFA & 15.3 & 16.5 & 17.7 \\
Total PUFA & 46.7 & 44.6 & 44.8 \\
Trans fatty acids & 0.41 & 0.61 & 0.26 \\
n-3 PUFA & 10.5 & 11.3 & 9.5 \\
n-6 PUFA & 36.1 & 33.3 & 35.3 \\
\hline
\end{tabular}

Table 2: Plasma fatty acids

\begin{tabular}{llll}
\hline & Belgium & UK & Italy \\
\hline Total fatty acids & 10,342 & 10,579 & 11,111 \\
Saturated (\%) & 28.4 & 29.1 & 28.8 \\
Total MUFA & 22.7 & 24.7 & 29.1 \\
Total PUFA & 48.3 & 45.5 & 41.6 \\
Trans fatty acids & 0.48 & 0.53 & 0.29 \\
n-3 PUFA & 4.8 & 5.4 & 3.8 \\
n-6 PUFA & 43.5 & 40.0 & 37.8 \\
\hline
\end{tabular}

These preliminary data (no statistics) indicate that there are differences between these populations. Analyses of plasma fatty acids seem to be more discriminant than that of red cell membranes. Obviously, Italian people eat less n-3 fatty acids than the British and Belgian. They also eat less n- 6 fatty acids and trans fatty acids, but probably more MUFA (oleic acid from olive oil very probably). In the same time, the concentration in total fatty acids in the plasma is the same in the three populations and there are, apparently, no difference for saturated fatty acids. From these preliminary data, we can conclude that the dietary habits of these three populations are probably different. However, the between-group variations were not totally expected, especially for $n-3$ fatty acids. This may be important, knowing the protective effect of $n-3$ fatty acids, in terms of CHD risk profile.

\section{Genetic Variation and Physical Performance}

John Payne, Hugh Montgomery

Royal Free and University College London Medical School, London, UK

Introduction

From our earliest years at school, we will all have recognised that some individuals seem more inherently 'gifted' in sporting prowess than others. Here we examine the role of genes in influencing physical performance by providing specific exemplars focussed on tissue renin-angiotensin systems (RAS).

Gene Interaction with an Exercise Stimulus in Determining Phenotype: Left Ventricular Hypertrophy as an Exemplar

Left ventricular (LV) mass differs markedly amongst normal individuals, even under similar conditions of work load [1-4], and it is 
likely that this diversity has a genetic basis. Given that LV growth occurs in response to exercise, we might expect a gene-dependent variation in cardiac growth response to exercise. Such a geneenvironment interaction is perhaps best demonstrated for genes encoding elements of human RAS.

Angiotensin-converting enzyme (ACE), converts angiotensin I to angiotensin II (Ang II) and degrades bradykinin. Ang II is a powerful cellular growth factor whose local synthesis in response to mechanical loading may drive cardiomyocyte growth, and bradykinin is recognised to have growth inhibiting properties in the myocardium. Hence, local myocardial ACE may be a key transducer of cardiac growth. If true, the I allele of the ACE I/D polymorphism, which is associated with low tissue ACE activity [5], may also be associated with an attenuated LV hypertrophic response to exercise. This hypothesis was tested in 140 male army recruits in whom the LV growth response to 10 weeks of intensive physical training was assessed using echocardiography, electrocardiography and beta-natriuretic peptide (BNP) measurement [6]. Mean LV mass increased by $+2.0 \mathrm{~g},+38.5 \mathrm{~g}$ and $+42.3 \mathrm{~g}$ for II, ID and DD genotypes respectively $(\mathrm{p}<0.0001)$. Consistent with these data, both the prevalence of electrocardiographically-defined LV hypertrophy and change in BNP were genotype-dependent, in a statistically significant manner. This association was later confirmed using the same model, but assessing LV growth using the more reproducible method of cardiac magnetic resonance imaging [7].

\section{ACE Genotype and Performance Phenotypes}

Whilst a body of cellular, animal and human data would support a role for ACE in the direct regulation of LV growth, it remains possible that ACE might exert a more indirect influence on LV hypertrophy. If local RAS were able to influence the efficiency or amount of work done for a given energy expenditure, of skeletal or cardiac muscle, one might expect differing magnitudes of adaptation (LV growth) to compensate for the increased exercise burden associated with training in the recruits, and that measures of performance may too be ACE genotype-dependent. Such evidence is accruing [8-11]. This text has room only to describe one such example. The mechanical efficiency of skeletal muscle, or 'Delta efficiency' (the ratio of the change in muscle work performed $/ \mathrm{min}$ to the change in energy expended $/ \mathrm{min}$ ) was measured in young male army recruits, and its response to a 10 -week exercise training programme assessed. This response was strongly genotype-dependent, with mean delta efficiency rising by $8.62 \%$ in those of II genotype, and falling slightly ( $-0.39 \%)$ amongst those of DD genotype [9].

These data support a role for lower ACE activity interacting with physical training in the regulation of metabolic efficiency. They suggest that increased RAS activity is associated with reduced metabolic efficiency.

\section{Does such Data Extrapolate to Disease States?}

Heart failure (HF) is associated with a detrimental increase in circulating RAS activity. A class of drugs known as ACE inhibitors have now become a mainstay in the treatment of heart failure, and an effect of ACE inhibition on ME has been postulated to account, in part, for the dramatic beneficial effects of treatment with ACE inhibitors in patients with HF [12]. Research to date supports this concept.

Intrinsic defects in metabolic function of skeletal muscle may be responsible $[13,14]$ for limiting physical performance in heart failure, making muscles less resistant to fatigue. Part of this metabolic failure may relate to reductions in the 'metabolic efficiency' of skeletal muscle with increasing amounts of evidence supporting this notion [15-17].

So the benefits of ACE inhibition in HF may well be mediated, at least in part, through such peripheral (skeletal muscle) metabolic effects rather than through central (cardio-respiratory) effects [12, 18].

\section{Summary}

We have briefly demonstrated some key advances in our understanding of the genetic contribution to variations in performance, and the benefits of using human gene-environment studies to understand physiological mechanisms in normal healthy individuals, gaining insights into more complex pathological processes such as heart failure.

\section{References}

1 Devereux RB: Left ventricular geometry, pathophysiology and prognosis. J Am Coll Cardiol 1995;25:885-887.

2 Post WS, Larson MG, Myers RH, et al: Heritability of left ventricular mass. Circulation 1994;90:I-283.

3 de Simone G, Daniels SR, Devereux RB, et al: Left ventricular mass and body size in normotensive children and adults: Assessment od allometric relations and impact of overweight. J Am Coll Cardiol 1992;20:1251-1260.

4 Kannel WB, Gordon T, Offutt D: Left ventricular hypertrophy by electrocardiogram. Prevalence, incidence and mortality in the Framingham study. Ann Int med 1969;71:89-101.

5 Danser AH, Schalekamp MA, Bax WA, et al: Angiotensin converting enzyme in the human heart. Effect of the deletion/insertion polymorphism. Circulation 1995;92:1387-1388.

6 Montgomery HE, Clarkson P, Dollery CM, et al: Association of angiotensinconverting enzyme gene I/D polymorphism with change in left ventricular mass in response to physical training. Circulation 1997;96:741-747.

7 Myerson S, Montgomery HE, Whittingham M, et al: Left ventricular hypertrophy with exercise and the angiotensin converting enzyme gene I/D polymorphism: A randomised controlled trial with Losartan. Circulation 2001;103:226-230.

8 Nazarov IB, Woods DR, Montgomery HE, et al: The angiotensin converting enzyme I/D polymorphism in Russian athletes. Eur J Hum Genet 2001;9:797-801.

9 Williams AG, Rayson MP, Jubb M, et al: The ACE gene and muscle performance. Nature 2000;403:614

10 Folland J, Leach B, Little T, et al: Angiotensin-converting enzyme genotype affects the response of human skeletal muscle to functional overload. Exp Physiol 2000;85:575-579.

11 Myerson S, Hemingway $\mathrm{H}$, Budget $\mathrm{R}$, et al: Human angiotensin Iconverting enzyme gene and endurance performance. J Appl Physiol 1999;87:1313-1316

12 Jondeau G, Dib JC, Dubourg O, et al: Relation of functional improvement in congestive heart failure after quinapril therapy to peripheral limitation. Am J Cardiol 1997;79:635-638.

13 Minotti JR, Christoph I, Oka R, et al: Impaired skeletal muscle function in patients with congestive heart failure. Relationship to systemic exercise performance. J Clin Invest 1991;88:2077-2082.

14 Harridge SD, Magnusson G, Gordon A: Skeletal muscle contractile characteristics and fatigue resistance in patients with chronic heart failure. Eur Heart J 1996;17:896-901.

15 Kemp GJ, Thompson CH, Stratton JR, et al: Abnormalities in exercising skeletal muscle in congestive heart failure can be explained in terms of decreased mitochondrial ATP synthesis, reduced metabolic efficiency, and increased glycogenolysis. Heart 1996;76:35-41.

16 Opasich C, Aquilani R, Dossena M, et al: Biochemical analysis of muscle biopsy in overnight fasting patients with severe chronic heart failure. Eur Heart J 1996;17:1686-1693.

17 Musch TI, Ghaul MR, Tranchitella V, et al: Skeletal muscle glycogen depletion during submaximal exercise in rats with chronic heart failure. Basic Res Cardiol 1990;85:606-618.

18 Imaizumi T, Takeshita A, Nakamura N, et al: Effects of captopril on forearm oxygen consumption during dynamic handgrip exercise in patients with congestive heart failure. Jpn Heart 1990;31:817-828. 


\section{Nutrient-Gene Interactions on Lipids and Metabolic Syndrome; Physical Activity and Reverse Cholesterol Transport}

\section{Paul Nestel}

\section{Baker Heart Research Institute, Melbourne, Australia}

This presentation will focus on 3 areas of nutrient-genelipoprotein-physical activity interactions.

1. Nutrient-gene interactions relevant to lipid/CHD issues had for many years investigated polymorphisms in the genes of regulatory enzymes, receptors, transfer proteins and apolipoproteins.

2. More recently, the spectacular increase in the prevalence of overweight/obesity and accompanying insulin resistance, has focused on the wide spectrum of relevant genes expressed in adipose tissue.

3. The recent discovery of the $\mathrm{ABC} \mathrm{A} 1$ gene has illuminated the process of reverse cholesterol transport (RCT) through which HDL mediates the flux of cholesterol from extrahepatic cells to the liver.

1. The interactions of dietary factors with genetic variations of lipid regulatory genes on the lipoprotein phenotype have shown several significant associations especially with respect to apolipoprotein E. Because of the association between apo E genotype and lipid concentrations (apo E4 linked to LDL and apo E2 to triglycerides and HDL), the possibility of an effect also on the lipoprotein response to dietary fat and cholesterol has been widely studied. Whereas several studies showed greater apo E4-LDL interaction with dietary fat, this finding was later found to be inconsistent. However a gender/diet interaction seems likely with men who carry the apo E4 gene showing a more consistent rise in LDL with dietary saturated fat and cholesterol. Post-prandial clearance of triglyceride-rich lipoproteins also appears impaired in people with the apo E4 genotype. By contrast the apo E2 genotype is more commonly associated with higher fasting triglyceride levels and with triglyceride overproduction in response to sugar consumption. Different post-prandial responses to eating fat have been reported also with apo A4 polymorphism.

2. The identification in adipose tissue of a storehouse of genes highly relevant to insulin resistance has provided a strong rationale for the linkage between obesity and the metabolic syndrome. The genes include lipoprotein lipase, leptin, glucocorticoids, PPAR $\gamma$, adiponectin, cytokines TNF $\alpha$ and interleukins, sterol regulatory element binding protein-1c, $11 \beta$ hydroxysterol dehydrogenase type 1 , angiotensinogen, plasminogen activator inhibitor-1, CD 36 and others. The linkages through adiposity to metabolic derangements characterising the metabolic syndrome are prime examples of nutrient-gene interactions. Polymorphisms in several of these genes either exacerbate or ameliorate the metabolic defect. Evidence has accrued from population studies and from mice transfected with the human genes and then fed high fat diets.

3. Mutation of the ABCA1 gene, rendering the gene product dysfunctional, prevents normal transfer of cholesterol out of cells and thus interferes with an early key step in reverse cholesterol transport (RCT). We have been interested in the next step, the formation of nascent HDL particles, pre $\beta-1$ HDL, disc shaped particles containing phospholipid and free cholesterol derived from the surface of cells, complexed to apo A1. RCT is difficult to quantify but pre $\beta-1 \mathrm{HDL}$ may be a robust biomarker for RCT activity. We have previously shown that when plasma from obese subjects is incubated with cells, the transfer of cellular cholesterol to pre $\beta-1 \mathrm{HDL}$ is proportional to BMI. Because physically fit people have increased levels of plasma HDL that may reflect enhanced RCT, we have carried out 2 studies in which the pre $\beta-1$ responses to physical exercise and fitness have been measured. The nature of HDL particles was evaluated across the circulation of the muscles in the legs of exercising subjects. The concentration of pre $\beta-1$ HDL in the femoral vein but not in the femoral artery rose substantially in the exercising leg strongly suggesting that cholesterol was released and RCT stimulated by exercise. Since pre $\beta-1$ HDL are eventually converted to mature HDL, we measured the concentration of pre $\beta-1$ HDL in elite athletes in whom total HDL levels were substantially higher than average. The levels of the precursor HDL particles were indeed found to be high in the athletes and furthermore correlated significantly with aerobic capacity as measured by VO2 max. The correlation between total HDL and VO2 max was much weaker. These studies demonstrate that physical exercise leading to aerobic fitness stimulates RCT, a process likely to be beneficial in reducing atherosclerosis.

\section{Interactions Between Candidate Genes, Nutritional and Lifestyle Factors in the Acquisition and Maintenance of Bone Mass}

\section{Serge Ferrari}

Division of Bone Diseases, WHO Collaborating Center for Osteoporosis, Geneva University Hospital, Geneva, Switzerland

Osteoporosis and related fractures represent near-epidemic public health concerns that are predicted to increase 2- to 8-fold in the next 50 years, as the population ages. Osteoporosis is a bone fragility disorder caused by low bone mass and deterioration of bone microarchitecture. Both men and women begin to lose bone mass in their forties but women experience a more rapid phase of bone loss after menopause, due to estrogen-deficiency that allows for bone resorption to overcome bone formation. However, recent data suggest that estradiol levels play a prominent role on bone mass in men as well. Bone loss continues in older persons and may actually increase with age. The major nutritional and lifestyle factors implicated in this process are dietary calcium and vitamin D insufficiency, with secondary hyperparathyroidism leading to increased bone turnover; low protein intake leading to decreased insulin-like growth factor (IGF-1) levels and impaired bone formation; and the absence of physical exercise, that concurs to decrease both bone mass and muscle strength, with an ensuing increased risk of falls and fractures. In addition to high bone remodeling in later years, the risk of osteoporosis is also determined by a low peak bone mass. Peak bone mass is achieved in the late second to third decade of life through a bone modeling process characterized by major changes in bone size and lesser changes in bone mineral density. Accordingly, differences in bone size greatly contribute to gender- and ethnicity-related differences in bone fragility and liability to fractures. Specifically, the lifetime risk of suffering an osteoporosis-related fracture exceeds $40 \%$ in women and $13 \%$ in men. Calcium and vitamin D intake in infancy and childhood, protein intake, physical exercise and estrogens, all play a prominent role on peak bone mass acquisition. In growing children (9-18 years-old), the current Adequate Intake (AI) for calcium 
is $1,300 \mathrm{mg} / \mathrm{d}$, whereas after 51 years of age, it is $1,200 \mathrm{mg} / \mathrm{d}$ in both males and females. However, as much as $50 \%$ or more of the concerned population in Western countries may not reach such calcium threshold, and the proportion of Asians with inadequate calcium intake is even higher. In turn, placebo-controlled trials have demonstrated the beneficial effects of calcium (and vitamin D) supplementation to promote bone mass growth during childhood and maintain bone mass and prevent fractures in aging women. However, in prepubertal boys with insufficient calcium intake but a high protein intake, we found little, if any, effects of calcium supplementation on bone mass gain. In addition, there are suggestions that calcium could interact with physical exercise to increase bone mass, although this remains to be proven by adequate prospective trials.

What about the influence of genetic factors on peak bone mass and bone loss? Twin and parent-offspring studies have indicated that additive genetic effects account for 60 to $80 \%$ of the population variance in bone mineral density, bone size and bone mass, similar to stature. In contrast, genetic factors appear to contribute for only about one third of the variance in the liability for fracture itself, which is easily explained by the fact that fracture is a stochastic event that not only depends on both strength but also on the extrinsic determinants of falls. Among the dozens of candidate genes investigated in population-based association studies for bone mass so far, two examples are particularly relevant to illustrate the importance and complexity of interactions between genetic and non-genetic factors on bone mass. The first pertains to the influence of vitamin $\mathrm{D}$ receptor gene 3'-UTR (Bsml) polymorphisms on the skeletal response to calcium. Several studies in various populations and age groups have shown that the relationship between calcium intake and bone mineral density might be better described by sigmoidal curves which point of inflection occurs at different calcium intake thresholds depending on vitamin D receptor (VDR) genotypes. Most interestingly, it has been proposed that these curves do not run parallel to eachother but might actually cross-over. In this case, the less common VDR genotype $(B B)$ that is associated with decreased bone mass at low calcium intake might actually be the one associated with increased bone mass at higher calcium intakes. Thus, the VDR $B B$ genotype would be characterized by a low efficiency-high capacity in promoting calcium absorption and/or bone mineralization. This might also explain why the $B B$ genotype is virtually absent among Asians, whose diet is traditionally poor in dairy products. This interpretation in keeping with our current understanding that many polymorphisms which appeared a few ten thousand years ago in the human genome of Caucasian ancestors as an adaptation to their changing environment have become inadequate to handle with our current nutritional habits. The second example of important interactions between gene polymorphisms and non-genetic factors affecting bone mass concerns allelic variants in the interleukin-6 (IL-6) gene promoter region. Consistent with the known role of interleukin-6 (IL-6) on mediating the effects of estrogen-deficiency to increase bone resorption and bone loss, linkage studies have identified the IL-6 gene locus to be associated with bone density in postmenopausal women and in families of osteoporotic probands, but not in younger healthy females. Thus, we reported that late postmenopausal women who carried the less common IL-6 promoter $-174 C C$ genotype had significantly lower bone resorption levels compared to $-174 G G$ women, bone resorption levels in the former actually being similar to premenopausal women. In the same cohort, hip bone mineral density was decreased by $5.5 \%$ in $70+$-year-old compared to $60+$-year-old $-174 C C$ women, whereas in $-174 G G$ women this difference was $10.0 \%$, suggesting that women carrying the $-174 C C$ genotype were actually protected against bone loss after the menopause. Others have reported an association between IL- 6 promoter polymorphisms and bone mineral density in Japanese subjects as well. We then examined the possible interaction between IL-6 promoter polymorphisms and factors known to affect bone turnover, namely years since menopause, oestrogen status, physical activity, smoking, dietary calcium, vitamin D and alcohol intake, in the Offspring Cohort of the Framingham Heart Study. This cohort comprises 1,574 unrelated men and women (mean age 60 years) with bone mineral density measurements at the hip. In models that considered only the main effects of IL-6 polymorphisms, no significant association with bone mineral density was observed. In contrast, interactions were found between IL-6 - 174 genotypes and years since menopause, oestrogen status, dietary calcium and vitamin D intake in women. Thus, bone mineral density was significantly lower with genotype $-174 G G$ compared to $C C$, and intermediate with $G C$, in women above 15 years past menopause, in those without estrogens or with calcium intake below $940 \mathrm{mg} / \mathrm{d}$. In oestrogen-deficient women with poor calcium intake, hip bone mineral density differences between IL-6 - 174 genotypes $C C$ and $G G$ were as high $16 \%$. In contrast, no such interactions were observed in men. These data therefore suggest that oestrogen replacement therapy and adequate calcium intake could be better targeted to population subgroups genetically identified to be at otherwise increased risk for accelerated bone resorption and low bone mass with aging.

In conclusion, these two examples provide a paradigm for the implications of nutrigenetics and pharmacogenetics in the osteoporosis field.

\section{Genetic Variation and Nutritional Requirements}

\section{Anne M. Molloy \\ Department of Biochemistry, Trinity College Dublin, Dublin, Ireland}

In recent years, investigations into determining the appropriate nutrition for long-term health have expanded into several exciting new areas. These include new insights into the importance of micronutrient intake and the role of genetic variance in modifying the bioavailability and function of these nutrients. Public health specialists have become aware that the requirements for vitamin and micronutrient intake go beyond the prevention of clinical deficiency and have an essential function in reducing risk of disease. This role of risk reduction covers broadly diverse conditions from cardiovascular disease and impaired cognitive function to cancer, birth defects and other complications of pregnancy. However, a major difficulty in setting out health recommendations is the fact that individuals differ in the amount of micronutrient intake required to reach a target optimal status. A principal reason for this is that, in addition to dietary influences, nutrient homeostasis is under constant genetic control. Furthermore, it is now apparent that these factors are not mutually exclusive. On the one hand, the bioavailability of a nutrient may be determined to a greater or lesser extent by genetic variants in enzymes that control its absorption, uptake, distribution or retention. On the other hand, the effect of genetic variants associated with poorer enzyme function may be modulated by higher intake and tissue status of the relevant nutrient. 
Table 1: Polymorphic SNPs forming potential gene-nutrient interaction sites in folate metabolism

\begin{tabular}{|c|c|c|c|}
\hline Metabolic area & Gene & Enzyme & Phenotype \\
\hline \multirow[t]{2}{*}{ Transport and binders } & $\begin{array}{l}\mathrm{RFC}-1 \\
80 \mathrm{G} \rightarrow \mathrm{A}\end{array}$ & $\begin{array}{l}\text { Reduced folate carrier } \\
\mathrm{H} 27 \mathrm{~N}\end{array}$ & $\begin{array}{l}\text { No reported risk association. Possible } \\
\text { interaction with nutrient intake }\end{array}$ \\
\hline & $\begin{array}{l}\text { FR } \alpha, \text { FR } \beta, \text { FR } \gamma \\
\text { Several SNPs }\end{array}$ & Folate binding proteins & $\begin{array}{l}\text { No reported risk associations or } \\
\text { biochemical changes }\end{array}$ \\
\hline $\begin{array}{l}\text { Provision of 5-methylfolate } \\
\text { for homocysteine remethylation }\end{array}$ & $\begin{array}{l}\text { MTHFR } \\
1298 \mathrm{~A} \rightarrow \mathrm{C}\end{array}$ & $\begin{array}{l}\text { As above } \\
\text { E429A }\end{array}$ & $\begin{array}{l}\text { No confirmed risk association. Possible } \\
\text { interactive effects with } 677 \mathrm{C} \rightarrow \mathrm{T}\end{array}$ \\
\hline $\begin{array}{l}\text { Remethylation of homocysteine } \\
\text { to methionine }\end{array}$ & $\begin{array}{l}\text { MS } \\
2756 \mathrm{~A} \rightarrow \mathrm{G}\end{array}$ & $\begin{array}{l}\text { Methionine synthase } \\
\text { D919G }\end{array}$ & $\begin{array}{l}\text { No risk association. Reported higher folate } \\
\text { status }\end{array}$ \\
\hline $\begin{array}{l}\text { Provision of one-carbon units primarily } \\
\text { for purine and pyrimidine synthesis }\end{array}$ & $\begin{array}{l}\text { MTHFD1 } \\
1958 \mathrm{G} \rightarrow \mathrm{A}\end{array}$ & $\begin{array}{l}\text { Trifunctional C1 synthase } \\
\text { R653Q }\end{array}$ & $\begin{array}{l}\text { Maternal risk factor for neural tube defects. } \\
\text { No reported change in folate status }\end{array}$ \\
\hline Pyrimidine synthesis & $\begin{array}{l}\text { TSER (Promoter enhancer } \\
\text { region) ( } 28 \text { bp double } \\
\text { or triple repeat) }\end{array}$ & Thymidylate synthetase & $\begin{array}{l}\text { Risk association with cancer depending on } \\
\text { folate intake }\end{array}$ \\
\hline Homocysteine catabolism & $\begin{array}{l}\text { CBS } \\
\text { 844ins68 }\end{array}$ & Cystathionine $\beta$ synthase & No risk association or biochemical changes \\
\hline
\end{tabular}

The vitamin folate provides a good example of where genetic make-up can influence an individual's achievable nutrient status and as a consequence, influence the risk of certain diseases. In a study of monozygotic twins, Mitchell et al. [1] calculated that at least $46 \%$ of the variation seen in red cell folate status is due to genetic variance. In the past few years, some of these genetic effects have been uncovered. Frosst et al. [2] were first to describe the 677C-T polymorphism in the enzyme methylenetetrahydrofolate reductase (MTHFR) and show that it conferred reduced enzyme activity. This is still the most important common variant known in folate metabolic pathways and there is now compelling evidence that it is associated with increased risk of certain disease conditions. The variant enzyme is associated with lower folate status as measured by low plasma and red cell folate [3]. Further evidence of impaired function is present in the form of elevated plasma levels of the highly reactive, toxic amino acid homocysteine that forms an essential intermediate in folate cofactor metabolism. Elevated plasma homocysteine is thought to be the vector through which increased risk of many of these chronic diseases is conferred.

Further complexities of this locus for gene-nutrient interaction have emerged in the past year. MTHFR requires a flavin cofactor and work on the $E$. coli form of the enzyme showed that the $677 \mathrm{C}-\mathrm{T}$ variant affected the binding affinity of the flavin cofactor for the enzyme but that binding could be stabilized by the presence of a high folate concentration [4]. In agreement with this, clinical studies have now shown that riboflavin status may be critical to maintaining adequate enzyme function in subjects with the variant TT genotype $[5,6]$. Thus, for the $5-20 \%$ of persons worldwide who are homozygous for this variant, the requirement for both folate and riboflavin may be greater than that for other individuals.
The Human Genome Sequencing Project has uncovered a multitude of common variants in enzymes controlling micronutrient homeostasis. Again, folate provides a good example of this variability. To date, several potentially important polymorphisms in folate enzymes have been examined in relation to phenotypic effects. These polymorphisms span the entire range of folate metabolism, from vitamin absorption, transport and uptake, to cofactor interconversions and metabolite utilization (table 1). While the phenotypic consequences are individually very small, in combination, these variants can predispose individuals to higher or lower plasma homocysteine and consequently may require more or less intake of folate to maintain an optimal status [7].

\section{References}

1 Mitchell LE, Duffy DL, Duffy P, Bellingham G, Martin NG: Genetic effects on variation in red-blood-cell folate in adults: Implications for the familial aggregation of neural tube defects. Am J Hum Genet 1997;60:433-438.

2 Frosst P, Blom HJ, Milos R, Goyette P, Sheppard CA, Matthews RG, Boers GJ, den Heijer M, Kluijmans LA, van den Heuvel LP, Rozen R: A candidate genetic risk factor for vascular disease: A common mutation in methylenetetrahydrofolate reductase. Nature Genet 1995;10:111-113.

3 Molloy AM, Daly S, Mills JL, Kirke PN, Whitehead AS, Ramsbottom D, Conley MR, Weir DG, Scott JM: Thermolabile variant of 5,10-methylenetetrahydrofolate reductase associated with low red-cell folates: Implications for folate intake recommendations. Lancet 1997;349:1591-1593.

4 Guenther BD, Sheppard CA, Tran P, Rozen R, Matthews RG, Ludwig ML: The structure and properties of methylenetetrahydrofolate reductase from Escherichia coli suggest how folate ameliorates human hyperhomocysteinemia. Nature Struct Biol 1999;6:359-365.

5 Hustad S, Ueland PM, Vollset SE, Zhang Y, Bjorke-Monsen AL, Schneede J: Riboflavin as a determinant of plasma total homocysteine: Effect modification by the methylenetetrahydrofolate reductase C677T polymorphism. Clin Chem 2000;46:1065-1071. 
6 McNulty H, McKinley MC, Wilson B, McPartlin J, Strain JJ, Weir DG, Scott JM: Impaired functioning of thermolabile methylenetetrahydrofolate reductase is dependent on riboflavin status: Implications for riboflavin requirements. Am J Clin Nutr 2002;76:436-441.

7 Molloy AM: Folate bioavailability and health. Int J Vitam Nutr Res 2002; 72:46-52.

\section{Genetic Control of Plasma Triglycerides}

Philippa J. Talmud

Royal Free and University College London Medical

School, London, UK

The meta-analysis by Hokanson and Austin [1] firmly established that raised plasma triglyceride (TG) levels are an independent risk factor for coronary heart disease (CHD). Thus identifying those factors that determine plasma TGs takes on a new level of importance. Environmental factors, especially diet, exercise and smoking, strongly determine TG levels, all of these are easily modifiable. However there are also genetic components, which cannot be modified, but identifying these genes and how they are modulated in a high-risk environment, suggests new mechanisms for controlling plasma TGs.

\section{Lipoprotein Lipase as a Candidate}

Lipoprotein lipase (LPL), bound to the vascular endothelium via membrane-anchored heparan-sulphate proteoglycans plays a central role in TG metabolism. LPL hydrolyzes the circulating TG-rich lipoproteins (TGRLs), resulting in the formation of chylomicron remnants and intermediate density lipoproteins (IDL), the VLDL remnants, and LDL. In addition, LPL has a non-enzymatic molecular 'bridging' function, acting as a ligand in lipoprotein-cell surface interactions, mediating cellular binding and uptake of lipoproteins [2]. This suggests that LPL may have anti-atherogenic effects by clearing circulating lipoproteins and pro-atherogenic effects by promoting the uptake of potentially atherogenic TGRLs by the arterial wall.

\section{Common LPL Variants and TG Levels}

Three common amino acid changes exist within the coding region of the LPL gene; D9N, N291S and S447X [reviewed in 3]. While N9 and S291 occur at carrier frequencies ranging from $1-6 \%$ in healthy Caucasian samples, and are associated with modest effects on TG of $11-14 \%$. X447 carrier frequency ranges from $11-23 \%$.

Unlike the other two common amino acid changes, the premature termination of LPL by 2 amino acids in the X447 variant appears to result in a lowering of TG levels by $8 \%$ and it is protective of CAD with an odds ratio of $0.8(95 \%$ CI $0.7-1.0)$ [4], although the exact mechanism is not known.

TG levels are subject to modulation by environmental factors such as diet, and exercise. Body mass index (BMI) is a surrogate marker of obesity, which reflects high caloric intake and/or reduced energy output. Several studies have shown individuals with low BMI who carry either $L P L$ N9 or $L P L$ S291 have only slightly higher TG levels than non carriers, while carriers who are in the higher range of BMI have significantly higher plasma TG levels than non carriers [3]. Since carriers of either of these mutations have approximately $30 \%$ lower post-heparin LPL activities, they would be expected to have slightly delayed clearance of TG-rich lipoproteins. The data suggest that in thin individuals who carry the variants, these lower LPL levels are adequate to maintain low levels of fasting TG-rich particles. However, in the obese, the increased secretion of VLDL from the liver overwhelms the partially impaired lipolytic system and hypertriglyceridemia develops.

\section{The APOA1-C3-A4-A5 Gene Cluster}

The mechanism by which apoC3 perturbs TG metabolism has been studied in vitro and high levels of apoC3 both inhibit LPL, thus reducing TG hydrolysis, and displace apoE from the particles, thus reducing clearance. apoC3 levels have been shown to be highly correlated with plasma TG levels confirming this strong mechanistic effect.

However with the identification, by comparative sequencing, of a new member of the apolipoprotein gene family, apoA5, an addition candidate was proposed [5]. APOA5 lies distal to $A P O A 4$ within the APOA1-C3-A4 cluster. Both knockout and transgenic mouse models confirm that apoA5 is having a major impact on TG metabolism. While the APOA5 knockout animal has very high TG levels the APOA 5 transgenic animal has low TG levels. This inverse relationship between TG and apoA5 levels suggests that apoA5 somehow maintains liver TG homeostasis, however the exact function of apoA5 remains unclear.

\section{APOC3 Variants Affect TG Levels and the Response to Fat and}

Glucose Challenges

The well studied SstI polymorphism $3238 \mathrm{C}>\mathrm{G}$ is in the $3^{\prime}$ untranslated region (3'UTR) of the APOC 3 gene and the rare C 3238 allele has consistently been associated with raised plasma TG and CAD [see 6]. The SstI site itself is thought unlikely to be of functional significance, but acts as a marker for a functional mutation elsewhere at the gene locus. The distal promoter of APOC3 is highly polymorphic, and some of these sites lie within an insulin responsive element (IRE) and affect the transcriptional activity of the gene [7]. Studies of the effect on APOC3 expression showed that one of these variants, $-482 \mathrm{~T}>\mathrm{C}$, within the IRE, led to the abolition of insulin responsiveness of the $A P O C 3$ promoter [8]. The $-482 \mathrm{~T}>\mathrm{C}$ is associated with differences in the response of insulin and glucose levels after an oral glucose load in young healthy men. In the same study, a second $A P O C 3$ variant in the $A P O C 3-A 4$ intergenic region, $-2854 \mathrm{~T}>\mathrm{G}$, was associated with response to an oral fat tolerance test. The -2854 site is very close to an HNF4 transcription factor binding site and the effects seen might be due to the linkage disequilibrium between these two sites and the possibility that the $-2854 \mathrm{~T}>\mathrm{G}$ is acting as a marker for the HNF4 site. Thus specific genetic variants at the APOC3 locus differentially affect postprandial TGs and response to an oral glucose load, and suggest a novel mechanism for the effects of variation at this locus on risk for atherosclerosis.

\section{APOA5 Variants Affect Plasma TG Levels}

The APOA5 gene although it is very polymorphic has three TG-determining haplotypes [9]. We have examined whether we could determine the relative contribution of the genes within the $A P O C-A 4-A 5$ cluster in determining TG levels [10].

\section{Conclusion}

It seems inevitable that the way forward, to tease out genetic factors affecting TG metabolism, and their effect on risk, must take into account environmental factors and other polygenic effects.

Acknowledgements

This work was supported by the British Heart Foundation. 


\section{References}

1 Hokanson JE, Austin MA: Plasma triglyceride level is a risk factor for cardiovascular disease independent of high-density lipoprotein cholesterol level: A meta-analysis of population-based prospective studies. J Cardiovasc Risk 1996;3:213-219.

2 Beisiegel U, Weber W, Bengtsson-Olivecrona G: Lipoprotein lipase enhances the binding of chylomicrons to low density lipoprotein receptorrelated protein. Proc Natl Acad Sci USA 1991;88:8342-8346.

3 Fisher RM, Humphries SE, Talmud PJ: Common variation in the lipoprotein lipase gene: Effects on plasma lipids and risk of atherosclerosis. Atherosclerosis 1998;135:145-159.

4 Wittrup HH, Tybjaerg Hansen A, Nordestgaard BG: Lipoprotein lipase mutations, plasma lipids and lipoproteins, and risk of ischemic heart disease: A meta-analysis. Circulation 1999;99:2901-2907.

5 Pennacchio LA, Olivier M, Hubacek JA, Cohen JC, Cox DR, Fruchart JC, Krauss RM, Rubin EM: An apolipoprotein influencing triglycerides in humans and mice revealed by comparative sequencing. Science 2001;294:169-173.

6 Talmud PJ, Humphries SE: Apolipoprotein C-III gene variation and dyslipidaemia. Curr Opin Lipidol 1997;8:154-158.

7 Dammerman M, Sandkuijl LA, Halaas JL, Chung W, Breslow JL: An apolipoprotein CIII haplotype protective against hypertriglyceridemia is specified by promoter and 3' untranslated region polymorphisms. Proc Natl Acad Sci USA 1993;90:4562-4566.

8 Li WW, Dammerman MM, Smith JD, Metzger S, Breslow JL, Leff T: Common genetic variation in the promoter of the human apo CIII gene abolishes regulation by insulin and may contribute to hypertriglyceridemia. J Clin Invest 1995;96:2601-2605.

9 Pennacchio LA, Olivier M, Hubacek JA, Krauss RM, Rubin EM, Cohen JC: Two independent apolipoprotein A5 haplotypes influence human plasma triglyceride levels. Human Molecular Genetics 2002;11:3031-3038.

10 Talmud PJ, Hawe E, Martin S, Olivier M, Miller GJ, Rubin EM, Pennacchio LA, Humphries SE: Relative contribution of variation within the APOC3-A4-A5 gene cluster in determining plasma triglycerides. Human Molecular Genetics 2002;11:3039-3046.

\section{Influence of Genetics on Responses to Dietary Components: The Quest for Personalized Recommendations}

\section{Jose M. Ordovas \\ Nutrition and Genomics Laboratory, JM-USDA-HNRCA at Tufts University, Boston, MA, USA}

Nutrigenomics is an emerging and promising multidisciplinary field that focuses on studying the interactions between nutritional, genetic factors, and health outcomes, using the new technical and conceptual developments derived, in part, from the human genome project. The ultimate goal of nutrigenomics is to elaborate more efficient individual dietary intervention strategies aimed to preventing disease and improving health status [1]. To date, gene-diet interactions have been carried out using the 'candidate gene' approach. Our studies using the Framingham Heart study as well as other population and intervention studies have found already significant evidence for interactions between dietary factors, genetic variants and biochemical markers of cardiovascular disease [2-4]. The traditional approach of recommending low fat, low cholesterol diets for the entire population has been the subject of heated discussion, based on the fact that some populations with relatively high intakes of non-saturated fats have very low rates of cardiovascular diseases and other chronic disorders. Now, we can begin to characterize individuals that may respond better to one type of recommendation or another. Therefore, a low fat, low cholesterol strategy may be especially beneficial in terms of lowering plasma cholesterol levels to those subjects carrying the apoE4 allele at the APOE gene [5]. The levels of HDL are modulated also by dietary, behavioral and genetic factors. We have recently reported that the effect of dietary PUFA intake on HDL-cholesterol concentrations is modulated by a common genetic polymorphism in the promoter region of the APOA1 gene. Thus, subjects carrying the A allele at the $-75 \mathrm{G} / \mathrm{A}$ polymorphism show an increase on HDL-C concentrations with increased intakes of PUFA; whereas those homozygotes for the more common $\mathrm{G}$ allele have the expected lowering on HDL-C levels as the intake of PUFA goes up [3]. We have also found significant interactions between intake of fat and variability at the hepatic lipase locus that could also shed some light to the different ability of certain ethnic groups to adapt to new nutritional environments [2]. At this regard we are carrying gene-diet interactions studies in Singapore, a country inhabited by three ethnic groups (Chinese, Indians and Malays) [4]. Our data is being contrasted with those obtained in Framingham in order to gain more understanding about potential gene-diet-ethnicity interactions. In addition to the more traditional dietary components, there have been several reports indicating that smoking, physical activity and alcohol drinking [6-10], significantly modulate the associations between genotypes and phenotypes. This should be taken into consideration when the time comes that we are ready to provide more personalized holistic recommendations to prevent disease and to achieve a healthier aging. This knowledge could pave the way for most successful dietary recommendations based on genetic factors that may help to reduce cardiovascular risk more efficiently than the current universal recommendations.

\section{References}

1 Ordovas JM: Gene-diet interaction and plasma lipid responses to dietary intervention. Biochem Soc Trans 2002;30:68-73.

2 Ordovas JM, Corella D, Demissie S, Cupples LA, Couture P, Coltell O, Wilson PW, Schaefer EJ, Tucker KL: Dietary fat intake determines the effect of a common polymorphism in the hepatic lipase gene promoter on high-density lipoprotein metabolism: Evidence of a strong dose effect in this gene-nutrient interaction in the Framingham Study. Circulation 2002;106:2315-2321.

3 Ordovas JM, Corella D, Cupples LA, Demissie S, Kelleher A, Coltell O, Wilson PW, Schaefer EJ, Tucker K: Polyunsaturated fatty acids modulate the effects of the APOA1 G-A polymorphism on HDL-cholesterol concentrations in a sex-specific manner: The Framingham Study. Am J Clin Nutr 2002;75:38-46.

4 Tai ES, Ordovas JM, Corella D, Deurenberg-Yap M, Chan E, Adiconis X, Chew SK, Loh LM, Tan CE: The TaqIB and $-629 \mathrm{C}>\mathrm{A}$ polymorphisms at the cholesteryl ester transfer protein locus: Associations with lipid levels in a multiethnic population. The 1998 Singapore National Health Survey. Clin Genet 2003;63:19-30.

5 Ordovas JM: Gene-diet interaction and plasma lipid response to dietary intervention. Curr Atheroscler Rep 2001;3:200-208.

6 Corella D, Guillen M, Saiz C, Portoles O, Sabater A, Folch J, Ordovas JM: Associations of LPL and APOC3 gene polymorphisms on plasma lipids in a Mediterranean population: Interaction with tobacco smoking and the APOE locus. J Lipid Res 2002;43:416-427.

7 Perez-Martinez P, Gomez P, Paz E, Marin C, Gavilan Moral E, LopezMiranda J, Ordovas JM, Fernandez de la Puebla RA, Perez-Jimenez F: Interaction between smoking and the Sstl polymorphism of the apo C-III gene determines plasma lipid response to diet. Nutr Metab Cardiovasc Dis 2001;11:237-243.

8 Senti M, Elosua R, Tomas M, Sala J, Masia R, Ordovas JM, Shen H, Marrugat J: Physical activity modulates the combined effect of a common variant of the lipoprotein lipase gene and smoking on serum triglyceride levels and high-density lipoprotein cholesterol in men. Hum Genet 2001;109:385-392.

9 Corella D, Guillen M, Saiz C, Portoles O, Sabater A, Cortina S, Folch J, Gonzalez JI, Ordovas JM: Environmental factors modulate the effect of 
the APOE genetic polymorphism on plasma lipid concentrations: Ecogenetic studies in a Mediterranean Spanish population. Metabolism 2001;50:936-944.

10 Corella D, Tucker K, Lahoz C, Coltell O, Cupples LA, Wilson PW, Schaefer EJ, Ordovas JM: Alcohol drinking determines the effect of the APOE locus on LDL-cholesterol concentrations in men: The Framingham offspring study. Am J Clin Nutr 2001;73:736-745.

\section{Outline of the Two Sardinian Regional Projects of Preventive Medicine}

Sergio Muntoni

Centre for Metabolic Diseases and Atherosclerosis, The ME.DI.CO. Association, Cagliari, Italy

In 1998, the Sardinian Government launched the first-generation triennial projects of medical research coupled with promotion of employment, to be assigned through call for proposal.

One such project was worked out by our Institution and approved by the Special Department of Sardinian Government. It was entitled 'Prevention and Early Diagnosis of Cardiovascular Disease', and was implemented in 3 years, with the employment of 9 researchers and the financial support by the Sardinian Government.

Random samples of general population from southern and northern Sardinia for a total of about 4,000 persons of both sexes and aged from 20 years on were enrolled. A wide range of clinical, biochemical and lifestyle data were collected, allowing determination of mean levels and distribution of risk factors for atherosclerosis and many other variables in Sardinia and comparison with the same parameters surveyed several times during the last two decades. Health education was performed using special booklets that were distributed to the general population.

The success of this project in terms of promotion of both health and employment was so great, that in 2002 the Sardinian Government assigned our Institution a further triennial project of preventive medicine coupled with employment. The project is entitled 'Risk Factors and Prevention of Cardiovascular Disease and Diabetes in Sardinia' and is still in progress. This time the financial support has been doubled, allowing the number of employed researchers to go up to 21 .

The program of this second-generation project has received those from European Union in which our Institution is participating as an Operating Unit. Such programs are:

1. CINDI (Communitywide Integrated Noncommunicable Diseases Intervention);

2. EDIPS (European Diabetes Prevention Study);

3. HEALTHY CITIES (a WHO program).

Moreover, national programs of research and intervention are being carried out. They are:

1. T1DM (Prediction and Prevention of Type 1 Diabetes) in both Sardinian children and NOD mice;

2. RISCARD (Implementation of the Italian Card of Cardiovascular Risk);

3. FORUM for Cardiovascular Disease Prevention in Italy;

4. E.C.M. (Continuing Medical Education), promoted by the Italian Ministry of Health, addressed to all the researchers in our project. The project is now in progress in the whole island of Sardinia. The numberless data we are collecting are of inestimable value from both the research and the health policy viewpoints. Moreover, a group of health workers with well-established skill will be exploitable in future programs of disease prevention and health promotion at the population level in Sardinia.

\section{Genetic Features of Isolated Populations: The Case of Sardinians}

\author{
Francesco Cucca
}

Dipartimento di Scienze Biomediche e Biotecnologie, University of Cagliari, Cagliari, Italy

The Mediterranean island of Sardinia is of special interest for human geneticists, because it is a large genetic isolate with a high incidence of many heritable diseases and a peculiar distribution of alleles at multiple loci. In particular Sardinia, together with Finland has the highest incidence in the world of Type 1 diabetes and one of the highest prevalence of multiple sclerosis. Thus, the prior knowledge of the genetic structure of the Sardinians is of primary relevance for mapping projects addressed to detect disease genes involved in these complex traits showing a strikingly high frequency in the island. Moreover, this population offers a unique possibility to evaluate the potential impact of environmental factors, such as the diet, in a genetically homogeneous background.

The origin of the Sardinians is still somewhat controversial. Direct evidence, based on ${ }^{14} \mathrm{C}$ dating carried out on fossil bones, indicates that humans were already present in Sardinia in the pre-Neolithic age, about 750 generations ago $(15,590 \pm 140 \mathrm{BP})$. Around 3,500 years BP the local population was of a substantial size (around 300,000 inhabitants), which is indicated by the presence of 7,000 fortified stone towers across the island. In the 29th century BP the Sardinians entered in contact with the Phoenicians who built some towns in the coastal regions while the most internal and isolated region of the island (the Barbagia region) was not affected at all by the Phoenicians or by the subsequent Carthaginian (25th century BP) and Roman (2,238 years ago) invasions. There is no evidence of large-scale admixture between populations from coastal and internal regions over the last 2,000 years.

In order to better understand the genetic structure of the Sardinian population, we have examined the distribution of variation genetic markers, such as the HLA-DRB1-DQA1-DQB1 and chromosome $\mathrm{Y}$ haplotypes in large sample sets of new-borns from different regions of the island. We found that the most frequent haplotypes were uniformly distributed in all regions, but at frequencies unique to Sardinia. Other haplotypes, common in other white European populations, are consistently rare or absent across the whole island. Analysis of molecular variance (AMOVA) showed a very low degree and non significant genetic differentiation between the coastal regions, which have suffered repeated invasions over many years, and the most internal and isolated part of the island. This suggests that there has been little genetic flow from the various populations that have invaded the island during the last 3,000 years, and that Sardinia, is a relatively homogeneous. These results indicate that robust casecontrol studies can be carried out in Sardinia without the spurious effects due to population stratification.

Moreover, the estimated age of the various chromosome Y mutations and their patterns of distribution in Sardinia and in Europe 
suggests that the bulk of the present time Sardinian population might have originated from ancestral, pre-Neolithic group(s) of founders with the possible further contribution of new arrivals in the Neolithic age.

Linkage disequilibrium (LD), the non random association of alleles at closely linked loci, is a genetic parameter providing further useful information about the genetic structure and demographic history of the human populations. Moreover, LD is being used to infer the location of unknown disease genes by virtue of their correlated appearance with surrounding markers. We have therefore analysed population specific factors influencing LD. To this aim we have contrasted intermarker LD results obtained in several chromosome regions analysed in large sample sets from the general Sardinian and UK populations. Moreover, to better analyse the demographic factors influencing LD we have also analysed a small sub-isolate represented by the Sardinian village of Gavoi. In comparison to what we observed in the UK and general Sardinian populations a dramatic increase of LD was found in the sub-isolate. The small population of the village of Gavoi over the course of its history appears as the critical factor that created considerable drift, accounting for the impressive LD observed in this sub-isolate. The size of the general Sardinian population is unlikely to have generated comparable levels of LD by drift. These results are clear evidence that small and isolated populations but not large genetic isolates exhibit higher levels of LD than the larger populations from which they are derived.

But what about the practical implications of these results for mapping projects of common disease genes? One of the most striking results is the strong degree of background LD found in the Sardinian sub-isolate. This suggests that these sorts of sub-isolates might represent ideal populations for the initial detection of polygenes involved in the predisposition to complex traits. In addition to the stronger background LD, there are other potential advantages in the choice of these sub-isolates. As a result of a reduced biochemical complexity and of a smaller number of disease alleles involved, some of the loci are expected to have stronger genetic effects on the trait under analysis. Furthermore, small isolates might contain mutations that are rare or non-existent in the larger population, thus allowing the identification of loci that would have been missed in the larger population.

One drawback in using such small populations for the LD analysis of common disease is that except for the most common diseases there will be few cases. Our recommendation is that such micro-isolates could be ideal in the search for markers in LD with quantitative trait underlying common disease endpoints. In QTL analyses all phenotyped individuals are included in the study. Once LD is obtained and replicated, the fine mapping of the region in LD could be carried out in the general Sardinian population.

In conclusion, our experimental data illustrates the advantages of the genetic analysis in the Sardinian population and allow a better understanding of the genetic structure of this isolated and ancient founder population.

\section{References}

Lampis R, Morelli L, Congia M, Macis MD, Mulargia A, Loddo M, De Virgiliis S, Marrosu M, Todd JA, Cucca F: The inter-regional distribution of HLA class II haplotypes indicates the suitability of the Sardinian population for case-control association studies in complex diseases. Hum Mol Genet 2000;9:2959-2965.

Lampis R, Morelli L, De Virgiliis S, Congia M, Cucca F: The distribution of HLA class II haplotypes reveals that the Sardinian population is genetically differentiated from the other Caucasian populations. Tissue Antigens 2000;6:515-521

International Conference on Genetic

Variation, Nutrition and Physical Activity
Zavattari P, Deidda E, Whalen M, Lampis R, Mulargia A, Loddo M, Eaves I, Mastio G, Todd JA, Cucca F: Major factors influencing linkage disequilibrium by analysis of different chromosome regions in distinct populations: Demography, chromosome recombination frequency and selection. Hum Mol Genet 2000;9:2947-2957.

Zavattari P, Lampis R, Mulargia A, Loddo M, Angius E, Todd JA, Cucca F: Confirmation of the DRB 1-DQB1 loci as the major component of IDDMI in the isolated founder population of Sardinia. Hum Mol Genet 2000;9:2967-2972.

\section{Gene-Nutrition Interaction in Type 1 Diabetes}

Sandro Muntoni

Center for Metabolic Diseases and Atherosclerosis, The ME.DI.CO. Association and Department of Biomedical Sciences and Biotechnologies, University School of Cagliari, Italy

Type 1 diabetes is an organ-specific autoimmune disease characterised by T-cell mediated autoimmune destruction of the pancreatic $\beta$-cells. Its aetiology is probably due to a combination of genetic and environmental factors. The disease is thus typically multifactorial. Wide geographic variation of Type 1 diabetes incidence worldwide has been reported, with a difference between the highest and lowest rates (per 100,000 per year) of about 60 -fold, ranging from 0.41 in Peru and 0.48 in China up to 40.2 in Finland. In the Mediterranean and neighbouring countries, the incidence rates of Type 1 diabetes under the age of 15 years also show wide variation, ranging from 3.2 in Macedonia to 36.6 in Sardinia. The genetic component of Type 1 diabetes cannot be classified according to a specific model of dominant, recessive or intermediate inheritance, but involves an interaction between different genes and environmental factors. The most important genes are within the major histocompatibility complex (MHC) HLA class II region on chromosome 6p21 (IDDM1), accounting for about $45 \%$ of the genetic clustering. Assessment of the respective roles of genetic and environmental factors in determining the different frequencies of Type 1 diabetes is an important task. In different geographical areas this is possible in two ways, by comparing either genetically different ethnic groups living in the same environment, or genetically identical populations living in different environments. Both epidemiological designs have been adopted in studies carried out on migrant populations in various countries of the world. Some results suggest a role for environmental factors, while several others are consistent with strong genetic determinants. A study by Laron group on different ethnic groups living in Israel showed striking differences in incidence of Type 1 diabetes. A striking increase in the disease was observed after 1985 in all ethnic subgroups of the Jewish population, but not in the Arabs, suggesting an influence of environmental agents linked to industrialisation and growing affluence. In the study on children of Sardinian ancestry born and living in the lowincidence Italian region of Lazio, we were able to compare the rates of Type 1 diabetes incidence both in children of the same ancestry living in two different regions and in children of two different ancestries born and living in the same region. Children from Lazio had a rate of 7.9, and from Sardinia 34.4. Children of Sardinian migrants to Lazio retained the same high incidence of the original population whether they were born in Sardinia just before migration (33.6) or 
were born in Lazio (33.8). Moreover, children with one Sardinian parent, either father or mother, had a rate (15.9) half that of Sardinians and double that of the indigenous population. The fact that Sardinian children have the same rate in Sardinia as in Lazio rules out any environmental factor specifically accounting for the much higher incidence in Sardinia as compared to Lazio. Full confirmation of these findings came from a migrant study in another Italian region, Lombardy, with the same low incidence of Type 1 diabetes as Lazio: children with one Sardinian parent have a relative risk of 2, and those born of two Sardinian parents a relative risk of 3.5. These studies of Sardinian migrants show beyond any doubt that the much higher incidence of Type 1 diabetes they have, compared to other neighbouring populations, is an exclusive consequence of their genetic features. In fact, Sardinians are a homogeneous population that originated from an early split in the Caucasian cluster and are genetically distinct from other European populations, including Italians. This is the basis of the differences in frequencies of some HLA haplotypes among Sardinians and other Caucasians, and hence of the peculiar proneness of Sardinians to Type 1 diabetes. The environmental risk determinants so far identified can be classified into three main groups; viral infections, toxins and diet. Among the latter, an increase in Type 1 diabetes risk has been associated with several nutrients. A positive association between Type 1 diabetes incidence and daily cow's milk intake was reported in several countries. Early exposure to cow's milk is strongly associated with diabetes in genetically prone subjects. In a nutritional ecological study we have shown that in 40 countries worldwide the incidence of childhood Type 1 diabetes is directly associated with average daily per capita energy intake of food items of animal origin and inversely with those of vegetal origin, having ruled out through multivariate analysis the influence of socioeconomic and geographic variables, such as gross domestic product (GDP) and average annual temperature. The food items we have found to be directly associated with Type 1 diabetes incidence in our worldwide nutritional survey are milk + dairy products $(\mathrm{r}=0.80, \mathrm{p}<0.0001)$ and meat $(\mathrm{r}=0.55, \mathrm{p}<0.001)$, while cereals are inverse predictors $(\mathrm{r}=-0.64, \mathrm{p}<0.001)$. Note that data from FAO have demonstrated that, during the period $1950-1989$, a $25 \%$ decrease in the availability of cereals and potatoes, and a $50 \%$ increase in the production of milk and meat occurred in Europe. These changes can well explain the worldwide increase in Type 1 diabetes incidence, each of the above reported items playing a specific role. Evidence is increasing that Type 1 diabetes is initiated in early childhood and that it may be a congenital or perinatal disease resulting in autoimmunity. It is plausible that amount and quality of energy intake in particular periods of life can influence the processes of $\beta$-cell injury and defense. Because insulin is a $\beta$-cell specific autoantigen, its augmented expression could increase the risk of developing Type 1 diabetes. Eating patterns at the population level appear to influence the risk of Type 1 diabetes, inasmuch as they reflect, statistically, the average eating patterns of pregnant and breastfeeding women, and of young children. The increasing dietary supply of animal protein (meat, milk and dairy products) after World War II may have contributed to the reported increasing incidence of Type 1 diabetes in wealthy European and non-European countries over the past several decades. Consistent with this view is the recently reported linear increase in Type 1 diabetes incidence with increasing birth weight as a consequence of augmented insulin secretion by foetal $\beta$-cells. The fact that the absolute increase in Type 1 diabetes is positively correlated with the incidence in a wide variety of populations is likely to reflect the influence of genetic factors in relation to ethnic diversity, and is consistent with our conclusion that in a given population genetic susceptibility determines the frequency of Type 1 diabetes in response to the environmental inducers or triggers. A more permissive environment would be expected to increase the penetrance of susceptibility alleles. Among these permissive factors we now include nutritional patterns. Such a view has important implications in setting up a strategy for Type 1 diabetes prevention through dietary manipulation, particularly in populations with a strong genetic proneness to the disease, such as Finns and Sardinians, in order to reverse its steadily increasing incidence. This kind of intervention would automatically include dietary habits that are common risk factors for other chronic non-communicable diseases.

\section{Epidemiology of Diagnosed and Undiagnosed Diabetes, and of IFG in Sardinia}

\section{Giovanni M. Baule}

Metabolic Diseases and Diabetes Unit - SS. Annunziata

Hospital, Sassari, Italy

Diabetes mellitus is a common disease in developed countries, although its prevalence seems to be underestimated [1]. Often symptoms are not severe, or may be absent, and consequently hyperglycaemia of sufficient degree to cause pathological changes may be present for a long time before the diagnosis is made.

The aim of this study was to evaluate the prevalence of diagnosed (DD) and undiagnosed (UD) diabetes mellitus and of Impaired Fasting Glucose (IFG) in a defined geographical area.

This study has been carried out in four different areas of Sardinia, an Italian island. Subjects over 20 years old were randomly stratified by decade and sex into seven groups. Blood samples were collected from each subject and tested for fasting glucose levels and metabolic values. Demographic data, eating habits, clinical history and treatment were recorded by a physician in a questionnaire. Patients with fasting plasma glucose of $126 \mathrm{mg} / \mathrm{dl}$ or greater were considered to have diabetes on the base of American Diabetes Society (ADA) Guidelines. Concentration between $\geq 110 \mathrm{mg} / \mathrm{dl}$ and $<126 \mathrm{mg} / \mathrm{dl}$ were considered as IFG [2].

Results

3,097 subjects were enrolled in the study (1,941 males, 1,156 females). 238 patients had fasting plasma glucose levels equal or above $126 \mathrm{mg} / \mathrm{dl}$. IFG was present in 210 subjects $(5.6 \% ; 9.4 \%$ males, $5.3 \%$ females) and diabetes in $282(9.1 \% ; 10.6 \%$ males, $8.2 \%$ females $)$. The newly-diagnosed cases of diabetes (UD) were $110(3.6 \% ; 4.2 \%$ males and $3.1 \%$ females), and $172(5.6 \% ; 6.3 \%$ males, $5.1 \%$ females) had a clinical history of diabetes (DD).

IFG increased with age up to the decade between the 60- and 69-year old (prevalence: $11.9 \%$ ).

The same trend was found for diabetic patients, but the highest prevalence (20.8\%) was reached in the following decade (DD: $13.9 \%$, UD: $6.9 \%$ ). In the diabetic group $23.8 \%$ were treated with insulin, $34.3 \%$ with a diet and $50 \%$ with oral hypoglycaemic drugs.

Insulin was the only therapy used in the first decade and was present in $75 \%$ of diabetics in the second decade. In the following age 
groups (40-49 and 50-59) the insulin treatment decreased up to the 60-69 decade, after which it rose again.

Oral hypoglycaemic drugs weren't used in the two youngest groups and increased in next ages. Diet as the only anti diabetic treatment was absent in the first decade and rose until $61.5 \%$ in diabetic subjects between 40 and 49 years old, decreasing in the older groups.

These results show that diabetes is widespread among Sardinians, even if its prevalence is lower than in other populations, being higher among males. Furthermore, we can remark the high prevalence of non-diagnosed and consequently untreated diabetes, in which the prevention of complications is obviously absent.

The prevalence of IFG $(5.6 \%)$ is very high; therefore, these subjects are at risk of developing diabetes if not adequately treated.

\section{Conclusions}

A reduction in the prevalence of non-diagnosed diabetes and IFG would be necessary. This is possible with an earlier diagnosis, prevention and correction of life style.

\section{References}

1 Harris MI, Flegal KM, Cowwie CC, Eberhardt MS, Goldstein DE, Little RR, Wiedmeyer HM, Byrd-Holt DD: Prevalence of diabetes, impaired fasting glucose, and impaired glucose tolerance in US adults. The Third National Health and Nutrition Examination Survey, 1988-1994. Diabetes Care 1998;21:518-524.

2 The Expert Committee on the Diagnosis and Classification of Diabetes Mellitus. Report of the Expert Committee on the Diagnosis and Classification of Diabetes Mellitus. Diabetes Care 1997;20:1183-1197.

\section{G6PD Deficiency: A Naturally-Occurring Model of HMG-CoA Reductase Restraint}

\section{Sergio Muntoni}

Centre for Metabolic Diseases and Atherosclerosis, The ME.DI.CO. Association, Cagliari, Italy

The enzyme glucose-6-phosphate dehydrogenase (G6PD) functions to reduce NADP while oxidising glucose-6-phosphate [1].

The G6PD gene is located on the $\mathrm{X}$ chromosome. A gene mutation entails lessened G6PD activity, that in the Mediterranean type is as low as $0-7 \%$ of normal [2], with the worst consequences in erythrocytes, which are particularly vulnerable to oxidative damage and undergo haemolysis after ingestion of fava beans or several drugs. However, the deficiency is also present in nucleated cells of many other tissues [3].

The highest prevalence of G6PD deficiency of Mediterranean type is among Kurdish Jews, up to $62 \%$ [1]. In some areas of Sardinia, G6PD-deficient males are over $40 \%$ [4].

Several metabolic consequences of this enzyme deficiency, besides haemolysis, have been described. The most frequently reported are lowered serum cholesterol and less cardiovascular disease. We have analysed the G6PD-deficiency prevalence in a cohort of 205 males with acute myocardial infarction and found a definite trend toward G6PDdeficiency lesser prevalence compared to the general population. Other important consequences are reduced myocyte/fibroblast proliferation, lowered mortality from liver cirrhosis, inverse relation between prevalence of G6PD deficiency and cancer. In a very recent study on 519 Sardinian patients with a large variety of malignant tumours we found that the prevalence of G6PD deficiency in males and females pooled together is significantly lower in cancer patients than in the general population of origin. That this phenomenon is not a consequence of an earlier mortality among persons with G6PD deficiency is demonstrated by a steady increase in prevalence of G6PD deficiency from $7.38 \%$ in stationary neoplasia to $9.78 \%$ in cancer progression up to $13.56 \%$ in the terminal stage, indicating a stronger resistance to the disease. We have observed an increase in prevalence of G6PD deficiency among elderly people ( $>80 \mathrm{yr}$ ): in deficient males 25.00 vs $17.11 \%$ (20-79 yr); in deficient females (totally + partially deficient) 31.58 vs $24.26 \%$ (20-79 yr). Although not statistically significant, this trend could indicate a favourable effect of G6PD deficiency on aging.

In circulating mononuclear cells from Sardinian G6PD-deficient males we have found (as compared with $100 \%$ in normal cells):

- G6PD basal activity: $11.1 \%$;

- basal free cholesterol synthesis (as 14C-acetate incorporation): 48\%;

- PHA-stimulated free cholesterol synthesis (as 14C-acetate incorporation): $45 \%$;

- basal DNA synthesis (as 3H-thymidine incorporation): 16\%;

- PHA-stimulated DNA synthesis (as 3H-thymidine incorporation): $40 \%$.

The depressed synthesis of cholesterol and DNA, both in the basal state and after stimulation, is the likely explanation of most of the above reported effects. Since cholesterogenesis and DNA replication are tightly linked through isoprenoid synthesis, the main consequence of G6PD deficiency at the cellular level is just the depressed synthesis of cholesterol and DNA. The active site of human HMG-CoA reductase is formed by the adjacent moieties of HMG, CoA, and NADP [5]. The reduced form of NADP (NADPH) is essential for the reductive deacylation of HMG-CoA to CoA and mevalonate. NADPH can be regenerated by the activity of G6PD in the first step of pentose phosphate pathway [1]. Thus, a deficiency of this enzyme results in impairment of mevalonate formation, and hence in lesser availability of mevalonate-derived substrates [6]. A comparison with two other conditions in which mevalonate generation is depressed can contribute to a better understanding of these phenomena. In the table 1 , the effects of statins, G6PD deficiency and dehydroepiandrosterone sulphate (DHEAS) are compared. All three conditions produce the same effects on a number of physiologic and pathologic events: these effects are named 'pleiotropic'. As a matter of fact, what is pleiotropic is the mevalonate pathway, with its steroidal and non-steroidal products [7].

It is therefore concluded that the manifold consequences of G6PD deficiency are a particular case of the more general phenomenon of HMG-CoA reductase down-regulation.

\section{Table 1}

\begin{tabular}{llll}
\hline & \multicolumn{2}{l}{$\begin{array}{l}\text { Low activity of HMG-CoA reductase } \\
\text { produced by }\end{array}$} \\
\cline { 2 - 4 } & Statins & $\begin{array}{l}\text { G6PD } \\
\text { deficiency }\end{array}$ & DHEAS \\
& & $\downarrow$ & $\downarrow$ \\
Plasma cholesterol levels & $\downarrow$ & $\downarrow$ & $\downarrow$ \\
All-cause mortality & $\downarrow$ & $\downarrow$ & $\downarrow$ \\
Cardiovascular disease & $\downarrow$ & $\downarrow$ & $\downarrow$ \\
Ischemic heart disease & $\downarrow$ & $\downarrow$ & $\downarrow$ \\
Cerebrovascular disease & $\downarrow$ & $\downarrow$ & $\downarrow$ \\
Myocyte/Fibroblast proliferation & $\downarrow$ & $\downarrow$ & $\downarrow$ \\
Liver cirrhosis & $\downarrow$ & $\downarrow$ & $\downarrow$ \\
Cancer & $\downarrow$ & $\downarrow$ & $\downarrow$ \\
Dementia & $\downarrow$ & $\downarrow$ & $\downarrow$ \\
Longevity & $\uparrow ?$ & $\uparrow$ & $\downarrow$ \\
\hline
\end{tabular}




\section{References}

1 Beutler E: Glucose-6-phosphate dehydrogenase deficiency. NEJM 1991;324:169-174.

2 Kirkman HN: Glucose-6-phosphate dehydrogenase variants and the drug-induced hemolysis. Ann NY Acad Sci 1968;151:753-764.

3 Battistuzzi G, D’Urso M, Toniolo D, Persico GM, Luzzatto L: Tissuespecific levels of human glucose-6-phosphate dehydrogenase correlate with methylation of specific sites at the $3^{\prime}$ end of the gene. PNAS USA 1985;82:1465-1469.

4 Sanna E, Bruno R, Cosseddu GG, Floris G, Salis A, Silvetti M: Presentday G-6-PD deficit in Sardinia with respect to malarial morbidity and mortality in the past. Z Morph Anthrop 1990;78:257-267.

5 Istvan ES, Deisenhofer J: Structural mechanism for statin inhibition of HMG-CoA reductase. Science 2001;292:1160-1164.

6 Siperstein MD: Role of cholesterogenesis and isoprenoid synthesis in DNA replication and cell growth. J Lipid Res 1984;25:1462-1468.

7 Goldstein JL, Brown MS: Regulation of the mevalonate pathway. Nature 1990;343:425-430.

\section{The Syndrome X: Gene-Environment Interaction}

\section{Gerald Reaven}

Stanford University School of Medicine, Stanford, CA, USA

The fact that we are now in the midst of an epidemic of both obesity and type 2 diabetes is well recognized. Some insight into why this is happening can be gained by consideration of the impact of cultural changes on the relationship between obesity and the pathogenesis of type 2 diabetes. Type 2 diabetes develops in the vast majority of individuals because they are insulin resistant, and can no longer secrete the large amounts of insulin necessary to compensate for the defect in insulin-mediated glucose disposal. The ability of insulin to simulate glucose uptake varies by at least six-fold in the population at large, with approximately $50 \%$ of the variability being related to the combination of an increase in adiposity $(25 \%)$ and a decrease in physical activity $(25 \%)$.

Although the gene, or more likely genes, that predispose an individual to be insulin resistant have not been identified, genetic differences almost certainly account for the remaining $50 \%$ of the variability in insulin action, and it is already clear that variations in insulin-mediated glucose disposal are at least familial. Furthermore, differences in ethnicity contribute substantially to the variability in insulin-mediated glucose disposal, with essentially every ethnic group of non-European ancestry being relatively insulin resistant. Thus, as the world becomes less physically active, and has greater access to calorically dense foods, it should not be too surprising that the numbers of individuals that are overweight/obese are rapidly increasing. Given a world that is now heavier and less fit, an increase in the prevalence of type 2 diabetes is predictable, and the observation that the epidemic is accentuated in non-European populations is entirely consistent with the greater degree of insulin resistance in these individuals.

Although the life-style changes noted can help explain the rapid increase in the prevalence of type 2 diabetes, it is not immediately clear why their impact is so powerful and the ethnic differences so great. One effort to account for these findings was the notion, initially proposed by James Neel, of a 'thrifty' genotype. Neel hypothesized that a 'quick insulin trigger' would be a useful evolutionary adaptation for primitive human beings, providing them with the means to maximize the utilization and storage of whatever food they could find to eat. This notion of a 'thrifty' genotype that makes more efficient the accumulation of ingested energy has become quite popular as a way to account for the current epidemics of obesity and type 2 diabetes. Unfortunately, it does not seem consistent with what we know about the pathophysiology of type 2 diabetes. For example, the notion that inheriting a 'quick insulin trigger' makes an individual more likely to become obese is not supported by available experimental evidence. Furthermore, if anything, having a decrease in the acute insulin response to nutrient ingestion appears to increase the risk of type 2 diabetes, where an exuberant one ('a quick insulin trigger') seems to decrease the likelihood that an insulin resistant individual will develop type 2 diabetes. Finally, if the adaptive advantage of 'a quick insulin trigger' were to maximize the utilization and storage of the nutrients absorbed, it would only have succeeded if the tissues responsible to perform this function were insulin sensitive. In other words, the hallmarks of the prediabetic individual, insulin resistance and a decrease in the acute insulin response, are exactly the opposite of what would have been predicted by the popular nation of the 'thrifty' genotype.

If insulin resistance is substituted for 'a quick insulin trigger', it is possible to construct an alternative view of the 'thrifty' genotype that is more consistent with our current view of the physiology of type 2 diabetes, and can also be viewed as having provided primitive human beings with a useful adaptive response. In the absence of food, muscle proteolysis is enhanced in order to provide amino acids for the liver to convert into glucose. In this situation, the less glucose utilized by the muscle, the more that is available to fulfill the obligatory requirements of the central nervous system and other tissues for glucose. By shunting glucose to tissues that required it, resistance to glucose uptake by muscle would decrease the amount of muscle required for hepatic gluconeogenesis, thus more effectively maintaining muscle mass during periods of caloric deprivation. In turn, the ability to maintain muscle mass would increase the likelihood that insulin resistant individuals would more successfully escape from predators and/or hunt for food. If insulin resistance was the 'thrifty' genotype, the more obese and physically inactive the population becomes, the more exaggerated will be the adverse consequences of what was once a useful adaptive response. Not only is this formulation consistent with the pathogenesis of type 2 diabetes, it provides a simple explanation for why weight loss and increased physical activity can prevent the progression of insulin resistant individual to develop frank hyperglycemia.

\section{Suggested Reading}

1 Neel JV: Diabetes mellitus; a 'thrifty' genotype rendered detrimental by 'progress'? Am J Hum Genet 1962;14:353-362.

2 Cahill GF Jr, Owen OE: Starvation and survival. Trans Amer Clin Climat Assoc 1967;79:13-20.

3 Wendorf M, Goldfine ID: Archaeology of NIDDM: Excavation of the 'thrifty' genotype. Diabetes 1991;40:161-165.

4 Reaven GM: Hypothesis: Muscle insulin resistance is the ('not-so') thrifty genotype. Diabetologia 1998;41:482-484. 


\section{Olive Oil Consumption and Health}

Antonio Capurso, Francesco Panza, Cristiano Capurso, Anna Maria Colacicco, Alessia D'Introno,

Francesco Torres, Vincenzo Solfrizzi

Department of Geriatrics, University of Bari, Bari, Italy

Olive oil, particularly the 'extra virgin' olive oil, is the main component of the 'Mediterranean diet'. In Apulia, South Italy, olive oil represents the main source of alimentary fats. $27-30 \%$ of total daily energy intake is given by fats, $80-85 \%$ of which derive from olive oil. The composition of 'extra virgin' olive oil is $70-80 \%$ monounsaturated n-9 oleic acid (MUFA), $8-10 \%$ poly-unsaturated n-6 linoleic acid (PUFA-LA), 1-2\% of poly-unsaturated n-3 linolenic acid (PUFA-LNA), and $7-8 \%$ of saturated palmitic acid.

In the Mediterranean basin, where large amounts of olive oil are consumed and consequently the MUFA intakes is particularly high, rates of coronary artery disease are low, as the total and CHD mortality. Moreover, epidemiological data on breast cancer prevalence have found an inverse association of breast cancer risk with MUFAs and a positive association with PUFAs. A MUFA rich diet but not a PUFA diet markedly lowers daily antihypertensive dosage requirement. Olive oil has been also found inversely associated with development of colorectal cancer. Plasma levels of total, LDL cholesterol, fasting blood glucose, and insulin levels have been found significantly higher on a linoleic acid-rich diet compared to an oleic acid-rich diet. Recent data in diabetic patients and a meta-analysis of available data indicates that linoleic acid lowers LDL cholesterol slightly more than does oleic acid, but not as much as it was previously reported. In a recent study, compared to the saturated fatty acid-rich diet, both the oleic and linoleic-rich diets significantly lowers plasma levels of total and LDL cholesterol and P-selectin.

In our recent studies we have found that neuropsychological test scores and macronutrient intakes are mutually independent, except for MUFA energy intakes which are significantly associated with an improved odds ratio of global cognitive functions and selective attention [1]. In a prospective cohort study high PUFA energy intake was positively associated with cognitive impairment in elderly subjects only in cross-sectional study, while at 3-year follow-up a high fish consumption tended to be inversely associated with cognitive impairment and cognitive decline [2].

Our group tested the hypothesis that high MUFA intake could protect against the development of cognitive impairment over time and whether this protection is MUFA dependent. Moreover, we tested also the role of PUFA intake in the senile mild cognitive impairment, the so called 'Age Related Cognitive Decline' (ARCD). Finally, we evaluated whether MUFA and/or PUFA intakes in older persons is associated to a protection from all-cause mortality.

The study (ILSA: Italian Longitudinal Study on Aging) was a randomized, cohort study with a median period of 8.5-year follow-up. The study include eight Italian municipalities and each cohort is composed of 704 subjects $65-84$ years old. A standardized test assessing global cognitive functions (Mini-Mental State Examination, MMSE) and a semi-quantitative food frequency questionnaire evaluating macronutrient energy intakes were performed. The subjects of our cohort that participated in the study were 278, 186 , and 95 nondemented elderly subjects evaluated respectively at the 1st (1992-1993), 2nd (1995-1996), and 3rd survey (2000-2001).

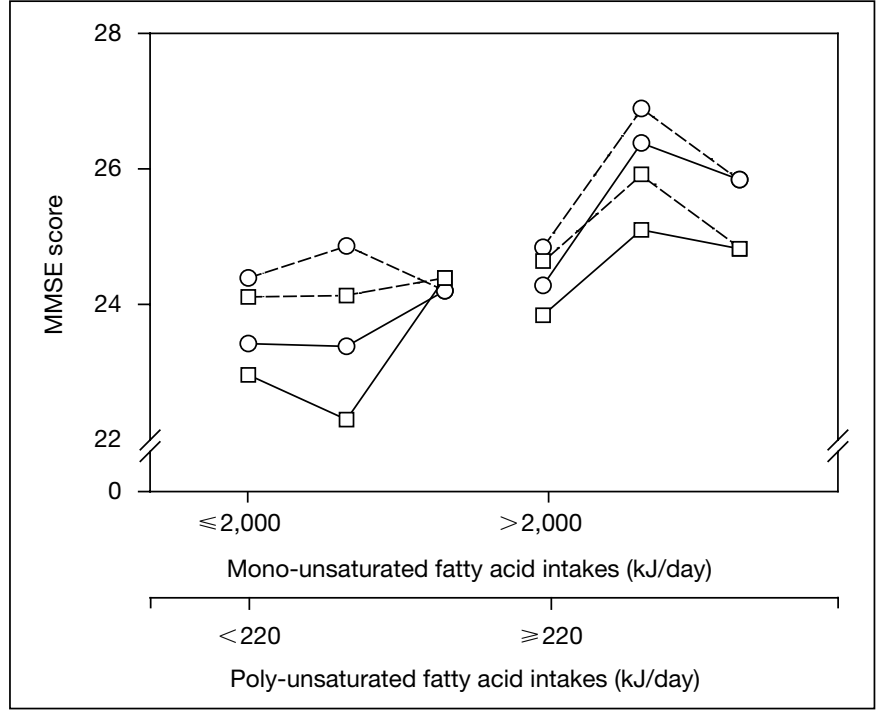

Fig. 1. Mean observed Mini-Mental State Examination (MMSE) score profile across time for MUFA $(\leq 2,000 \mathrm{~kJ} /$ day and $>2,000 \mathrm{~kJ} /$ day at the beginning of the study) and PUFA intake categories $(<220 \mathrm{~kJ} /$ day and $\geq 220 \mathrm{~kJ} /$ day at the beginning of the study), the Italian Longitudinal Study on Aging, 1992-2001. The circle and squared symbols and solid represent the mean observed MMSE scores for MUFA and PUFA intakes, respectively, computed using all observations ( $\mathrm{n}=278$ subjects), while the circle and squared symbols and short dashed line represent the mean MMSE scores for MUFA and PUFA intakes, respectively, computed data from 95 subjects with complete observations.

The major finding of our study was that the MMSE scores over 9 years follow-up in subjects with higher PUFA ( $\geq 220 \mathrm{~kJ} /$ day) and MUFA $(>2,000 \mathrm{~kJ} /$ day) intakes were higher than those of the subjects with lower PUFA $(<220 \mathrm{~kJ} /$ day $)$ and MUFA $(\leq 2,000 \mathrm{~kJ} /$ day $)$ intakes (fig. 1). Low MUFA intakes $(\leq 1,600 \mathrm{~kJ} /$ day) were also statistically significant predictor of all-cause mortality (fig. 2), while no effect of PUFA intake on all-cause mortality was found.

The mechanisms by which elevated unsaturated fatty acids intake could be protective against cognitive decline in healthy older people are, at present, unknown. This effect could be related to the role of fatty acids in maintaining the structural integrity of neuronal membranes. In fact, dietary fatty acids, in particular PUFAs, may determine the fluidity of synaptosomal membranes and thereby regulate neuronal transmission [3]. Furthermore, essential fatty acids can modify the activity of certain membrane-bound enzymes (phospholipase A2, protein kinase $\mathrm{C}$, and acetyltransferase) and the function of the neurotransmitters' receptors [3]. Free fatty acids, lipid metabolites, and phospholipids modify the function of membrane proteins including ion channels. Moreover, studies on fatty acid composition of neuronal membranes have demonstrated an increase in MUFA content and a decrease in PUFA content in advancing age [3]. Rats administered diets high in SFA or PUFA were impaired on various tests of learning and memory [3]. These findings are consistent with a recent study in which high PUFA intake is positively associated with cognitive impairment in elderly subjects, while high fish consumption tended to be inversely associated with cognitive 


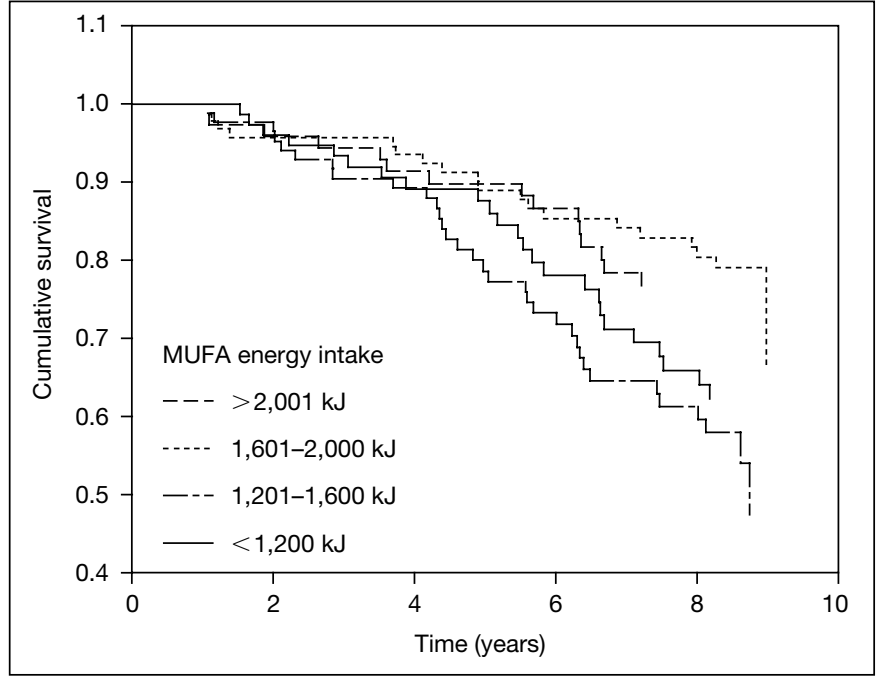

Fig. 2. Cumulative survival curves by MUFA intake (solid line for $\leq 1,200 \mathrm{~kJ} /$ day, dashed-dotted line for $1,201-1,600 \mathrm{~kJ} /$ day, dotted line for 1,601-2,000, and dashed line for $>2,000 \mathrm{~kJ} /$ day MUFA energy intake) categories adjusted for age, Charlson comorbidity index at baseline, and sex, the Italian Longitudinal Study on Aging, 1992-2001.

impairment in a 3-year follow-up too [2]. There are several studies on human infant subjects in which breastfeeding, which leads to higher n-3 PUFA (docosahexaenoic acid, DHA) concentrations in the brain, or n-3 PUFA supplementation, is related to better cognitive performance at later age. There are also evidences associating a dietary deficiency of n-3 PUFA with changes in cortical dopoaminergic function. While there are biologically plausible mechanisms between n-3 and cognitive functioning, findings on the possible role of n-6 PUFA, as seen above, are controversial [2]. In fact, high LA intake (n-6 PUFA) may increase the susceptibility of low-density lipoprotein (LDL) cholesterol to oxidation, which makes it more atherogenic, even if the association between LA and atherosclerosis is still controversial. Therefore the ratio of dietary n-3/n-6 PUFA intake may influence the potential role of PUFA on ARCD and the optimal ratio of $n-6: n-3$ should be $<5: 1$.

\section{References}

1 Solfrizzi V, Panza F, Torres F, Mastroianni F, Del Parigi A, Venezia A, Capurso A: High monounsaturated fatty acids intake protects against age-related cognitive decline. Neurology 1999;52:1563-1569.

2 Kalmijn S, Feskens EJ, Launer LJ, Kromhout D: Polyunsaturated fatty acids, antioxidants, and cognitive functions in very old men. Am J Epidemiol 1997; 145:33-41.

3 Solfrizzi V, Panza F, Capurso A: The role of diet in cognitive decline. J Neural Transm 2003;110:95-110.

\section{Wine Consumption and Health}

\section{Gino Farchi}

Laboratorio di Epidemiologia e Biostatistica, Istituto Superiore di Sanità, Rome, Italy

Epidemiological studies repeatedly showed that middle aged men and women who drink regularly a moderate amount of alcoholic beverages have lower death mortality rates from all causes and particularly from coronary heart disease and thrombotic stroke, in comparison with abstainers and heavy drinkers [1-3]. In middle-aged people, these results are consistent across ecological, case-control, and prospective studies, for different types of alcoholic beverages, wherever they were carried out. Particularly meaningful are the results of the most recent cohort studies which involved several hundred thousands people. Controlling for confounders seldom modifies significantly the results. A similar consistency was found in most studies, showing on the other hand, that alcohol drinkers experience higher mortality rates from cirrhosis, specific cancers, haemorrhagic stroke, violence, and accidents. The overall balance of risks and benefits depends on age and sex and is very different between, for example, a young woman and an adult man. This overall balance is summarised in total mortality.

Recently, the 'International Journal of Epidemiology' reprinted a paper written by Michael Marmot in 1984 on the relationship between alcohol and coronary heart disease [4]. The paper is followed by some commentaries. In my opinion, this series of papers thoroughly describe and correctly analyse the status of the updated epidemiological evidence in the field.

Some interesting news refer to two topics: the type of beverage and the pattern of drinking. Marmot says that 'There was a great deal of interest then, as now, in whether wine may be more protective than other beverages. There are at least three reasons why wine could appear to be more protective: it may contain substances other than alcohol, biophenols for example; wine drinkers may be different from other beverage consumers e.g. higher socioeconomic position; the pattern of drinking wine may differ from the pattern of drinking other beverages.... Two recent pieces of evidence, one from Keil and one from my own group, confirm my view that it is the alcohol in wine that is protective rather than other substances, although pattern of drinking may be important'.

Some Italian epidemiological studies gave a contribute to this scientific evidence.

\section{First study [5]}

In 1965, a total of 1,536 Italian males aged 45 to 65 years (two rural cohorts of the Seven Countries Study) underwent an examination which included: a general questionnaire, anthropometric measurements, an overall physical examination, ECG recording, blood pressure and serum cholesterol measurements, measurement of food consumption including alcohol. During a period of 30 years, from 1965 to 1995 , 1,096 deaths occurred. Age-adjusted life expectancy for men assuming daily a mean quantity of $63 \mathrm{~g}$ of alcohol (range 4-7 drinks per day) was $21.6 \pm 0.4$ years, roughly 2 years more than men taking a mean quantity of $3.7 \mathrm{~g}$ ( 1 drink or less) and men consuming more than 10 drinks per day. Taking into account smoking habit, the longest survival of $22.4 \pm 0.5$ years was observed in non-smokers drinking daily 4 up to 7 drinks; the lowest, $18.5 \pm 0.7$, in smokers drinking more than 10 drinks. Stratifying for 
physical activity, the longest survival $-23.4 \pm 0.7$ years - was experienced by men engaged in heavy physical activity at work drinking 1 up to 4 drinks per day.

\section{Second study [6]}

The Risk Factors and Life Expectancy Study, is a pooling of a series of epidemiological studies conducted in Italy. 8,647 men and 6,521 women, age 30-59 at baseline, and free of cardiovascular disease were followed for mortality from all causes, cardiovascular and non-cardiovascular causes during an average follow-up of seven years.

Drinkers of wine outside meals had higher death rates from allcauses, non-cardiovascular diseases and cancer compared to drinkers of wine with meals. This association was independent from the CVD risk factors measured at baseline and the amount of alcohol consumed and appeared to be stronger in women compared to men. The results indicate that drinking patterns may have important health implications and attention should be paid to this aspect of the alcohol consumption and its relationship with health outcomes.

Based on the evidence, the Dietary Guidelines for Americans 2000 state:

- If you choose to drink alcoholic beverages, do so sensibly, and in moderation.

- Limit intake to one drink per day for women or two per day for men, and take with meals to slow alcohol absorption.

- Avoid drinking before or when driving, or whenever it puts you or other at risk.

In our opinion this is the more comprehensive and complete recommendation on alcohol use.

The life expectancies of Italian and Sardinian people are reported in table 1 .

Life expectancy at birth in Sardinia is slightly lower than that in the whole Italy, but life expectancies at 65-years and 75-years are slightly higher especially for men.

Life styles in Italy and Sardinia are summarised in table 2.

Table 1: Life expectancy in Italy and Sardinia. ISTAT, year 1999

\begin{tabular}{|c|c|c|c|c|c|c|}
\hline & \multicolumn{2}{|c|}{ At birth } & \multicolumn{2}{|c|}{ At 65 years } & \multicolumn{2}{|c|}{ At 75 years } \\
\hline & Men & Women & Men & Women & Men & Women \\
\hline Italy & 76.0 & 82.1 & 16.2 & 20.2 & 9.7 & 12.3 \\
\hline Sardinia & 75.8 & 82.2 & 16.6 & 20.2 & 10.2 & 12.1 \\
\hline
\end{tabular}

Table 2: Life styles in Italy and Sardinia (age-standardised prevalence per 100). ISTAT, year 2000

\begin{tabular}{lrrrrr}
\hline \multirow{2}{*}{ Life styles } & \multicolumn{2}{l}{ Italy } & & \multicolumn{2}{l}{ Sardinia } \\
\cline { 2 - 3 } \cline { 5 - 6 } \cline { 5 - 6 } & Men & Women & & Men & Women \\
\hline Wine drinkers & 70.5 & 44.7 & & 66.4 & 33.3 \\
Wine drinkers (1/2 litre or more) & 9.8 & 2.0 & & 8.1 & 0.9 \\
Beer drinkers & 62.1 & 33.9 & & 68.7 & 34.7 \\
Beer drinkers (1/2 litre or more) & 2.1 & 0.3 & & 5.9 & 0.6 \\
Alcoholics outside meals & 35.1 & 12.4 & & 47.2 & 13.6 \\
Overweight or obese & \multicolumn{2}{c}{42.9} & & \multicolumn{2}{c}{40.3} \\
Smokers & 22.9 & & \multicolumn{2}{c}{21.9} \\
Light physical activity & \multicolumn{2}{c}{11.2} & & \multicolumn{2}{c}{10.8} \\
\hline
\end{tabular}

International Conference on Genetic

Variation, Nutrition and Physical Activity
Life habits in Sardinia, slightly better than those in the whole Italy, may explain the life expectancy gain in adults and elderly people.

\section{References}

1 Boffetta P, Garfinkel L: Alcohol drinking and mortality among men enrolled in an American Cancer Society prospective study. Epidemiology 1990;338:464-486.

2 Stampfer MJ, Colditz GC, Willet WC, et al: A prospective study of moderate alcohol consumption and the risk of coronary disease and stroke in women. N Engl J Med 1988;319:267-273.

3 Klatsky AL, Armstrong MA, Friedman GD: Risk of cardiovascular mortality in alcohol drinkers, ex drinkers and non-drinkers. Am J Cardiol 1990;66:1237-1242.

4 Marmot MG: Alcohol and coronary heart disease. Int J Epidemiol 2001; 30:724-729.

5 Farchi G, Fidanza F, Giampaoli S, et al: Alcohol and survival in the Italian rural cohorts of the Seven Countries Study. Int J Epidemiol 2000;29: 667-671.

6 Trevisan M, Schisterman E, Menotti A, et al: Drinking pattern and mortality: The Italian risk factor and life expectancy project. Ann Epidemiol 2001;11:312-319.

\section{Lactose Intolerance}

Antonio Cao, Mauro Congia

Dipartimento di Scienze Biomediche e Biotecnologie, Università di Cagliari, Cagliari, Italy

Lactose intolerance is due to low levels of lactase-phlorizin hydrolase (LPH) in the brush border of the small-intestinal enterocytes with the consequent inability to digest lactose into its constituents, glucose and galactose. Two forms with deficiency of lactase are recognized: the adult lactase deficiency and the congenital lactase deficiency $(C L D)$. A third condition of lactose intolerance having serious consequences in infants but associated with a normal presence of lactase in enterocytes is the congenital lactose intolerance.

Congenital lactase deficiency is a rare recessive disease. Usually, the mother notes a watery diarrhea, generally after the first feed of breast milk or at the latest within the next 10 days. Since 1966, 42 patients have been diagnosed in Finland and 18 elsewhere [1]. It is characterized by an almost total lack LPH activity on jejunal biopsy.

No mutation leading to a missense, frameshift, or other change in amino acid sequence was found after sequencing of the exons, the exon-intron boundaries, and the promoter region of the lactase gene (LCT) of a Finnish patient with congenital lactase deficiency [2].

The locus for congenital lactase deficiency maps to $2 \mathrm{q} 21$ in a zone separate $(>2 \mathrm{Mb})$ from the lactase gene also mapping to $2 \mathrm{q} 21$ [1].

Congenital lactose intolerance is due to an abnormal absorption of lactose and other disaccharides with lactosuria from the gastric mucosa (lactosuria disappears when lactose is given intraduodenally). It is a serious disorder with vomiting, failure to thrive, dehydration, renal tubular acidosis, aminoaciduria, liver damage and cataracts. A milk-free diet leads to rapid recovery, and after 6 months of age a normal diet (with milk) is well tolerated. The gene for this rare disorder has not yet been found

Adult lactase deficiency is the most common form of disaccharidase deficiency. The expression of lactase in adults is polymorphic with large differences in allele frequency among human populations [3]. Enzyme levels are highest shortly after birth and decline after 
weaning and with aging independently of a continued lactose intake. However, in many individuals lactase persists into adult life. Lactase persistence tends to be the most frequent phenotype in populations where fresh milk forms a significant part of the adult diet like Northern Europeans and pastoral nomadic tribes. Lactase-nonpersistent adults can usually consume only limited amounts of fresh milk without experiencing abdominal bloating, pain, flatulence, nausea, borborygmi and diarrhea.

Diagnosis or suggestion of lactose intolerance leads many people to avoid milk and/or consume specially prepared food with digestive aids, adding to health care costs.

Morbidity is low; the condition is not lethal. The only reported possible complication of adult-onset lactase decline may be osteopenia. Lactose intolerance seems a risk factor for osteoporosis, owing to avoidance of dairy products or interference of undigested lactose with calcium absorption [4].

By using known exons DNA 'marker' polymorphisms of the lactase gene, the expression of lactase mRNA transcripts in persistent and non-persistent individuals was examined to determine whether the regulation is in cis or trans. Results showed that in some lactasepersistent individuals one allele is expressed at much lower levels than the other. It was proposed that these individuals, having intermediate lactase activities, are heterozygous, implying that the nucleotide substitutions responsible for the lactase persistence/nonpersistence phenotype are cis-acting [5]. The authors have also shown that the genetically programmed down-regulation of the lactase gene is detectable starting from the second year of life [6].

A recent study using 11-site haplotype in 1,338 chromosomes from 11 populations differing in lactase persistence frequency [7] showed that haplotype diversity was generated both by point mutations and recombinations. Four globally common haplotypes (A, B, $\mathrm{C}$, and $\mathrm{U}$ ) not closely related and with different distributions have been found; the A haplotype is frequent only in northern Europeans, where lactase persistence is common, and the $U$ haplotype is virtually absent from Indo-European populations. Much more diversity occurs in sub-Saharan Africans than in non-Africans, consistent with an 'out of Africa' model for peopling of the Old World. Analysis of recent recombinant haplotypes, along with deduction of the root haplotype from chimpanzee sequence, allowed to define the relative roles of drift and selection in establishing the haplotype frequencies in different populations [7]. Genetic drift has been suggested as important force in shaping the general pattern of non-African haplotype diversity, with recent directional selection in northern Europeans for the haplotype associated with lactase persistence [7].

More recently, a complete association between biochemically verified lactase nonpersistence in Finnish families and a C/T $(-13,910)$ polymorphism roughly $14 \mathrm{~kb}$ upstream of the lactase gene locus on $2 \mathrm{q} 21$ has been found [8]. The $\mathrm{C}$ allele associated with hypolactasia and its presence in 1,047 DNA samples was consistent with the reported prevalence of adult-type hypolactasia in 4 populations. Thus, all individuals with lactase deficiency of the adult type were homozygous with respect to the $\mathrm{C}$ allele [8]. The finding of the association in different, distantly related populations suggests that the persistence allele is old and occurred long before the differentiation of these populations. The finding is in agreement with the hypothesis that adult lactase persistence has become more prevalent since the introduction of dairy culture approximately 10,000 to $8,000 \mathrm{BC}$ [9]. A selection power of 3 to $5 \%$ would be sufficient to explain the present frequency of the lactase persistence allele in northern Europe, assuming it arose around the advent of dairy culture $[10,11]$.

\section{References}

1 Jarvela I, Enattah NS, Kokkonen J, Varilo T, Savilahti E, Peltonen L: Assignment of the locus for congenital lactase deficiency to 2q21, in the vicinity of but separate from the lactase-phlorizin hydrolase gene. Am J Hum Genet 1998;63:1078-1085.

2 Poggi V, Sebastio G: Molecular analysis of the lactase gene in the congenital lactase deficiency. Am J Hum Genet 1991;49(suppl): 105.

3 Swallow DM, Poulter M, Hollox EJ: Intolerance to lactose and other dietary sugars. Drug Metab Dispos 2001;29:513-516.

4 Lee MF, Krasinski SD: Human adult-onset lactase decline: An update. Nutr Rev 1998;56:1-8.

5 Wang Y, Harvey CB, Pratt WS, Sams VR, Sarner M, Rossi M, Auricchio S, Swallow DM: The lactase persistence/non-persistence polymorphism is controlled by a cis-acting element. Hum Mol Genet 1995;4:657-662.

6 Wang Y, Harvey CB, Hollox EJ, Phillips AD, Poulter M, Clay P, WalkerSmith JA, Swallow DM: The genetically programmed down-regulation of lactase in children. Gastroenterology 1998;114:1230-1236.

7 Hollox EJ, Poulter M, Zvarik M, Ferak V, Krause A, Jenkins T, Saha N, Kozlov AI, Swallow DM: Lactase haplotype diversity in the Old World. Am J Hum Genet 2001;68:160-172.

8 Enattah NS, Sahi T, Savilahti E, Terwilliger JD, Peltonen L, Jarvela I: Identification of a variant associated with adult-type hypolactasia. Nat Genet 2002;30:233-237.

9 Holden C, Mace R: Phylogenetic analysis of the evolution of lactose digestion in adults. Hum Biol 1997;69:605-628.

10 Charney M, McCracken RD: Intestinal lactase deficiency in adult nonhuman primates: Implications for selection pressures in man. Soc Biol 1971;18:416-421.

11 McCracken RD: Origins and implications of the distribution of adult lactase deficiency in human populations. J Trop Pediatr Environ Child Health 1971;17:7-10.

\section{How to Face Stroke}

Cesare Fieschi

Clinica Neurologica, II Facoltà di Medicina e Chirurgia, Università La Sapienza di Roma, Rome, Italy

Although stroke severity decreases, its incidence increases all over the world, due to the growing number of older individuals in the population. Therefore, in the future stroke will still be a major threat for health, probably more than it is now. The implementation of measures aimed at limiting the burden of stroke should therefore become a priority at a national and international level. Different levels of intervention are needed. The first and foremost intervention is probably the transformation of the present 'spontaneous' or disorganized approach to care of acute stroke into an organized system of care based on dedicated wards or teams. Patients with acute stroke have a substantially better outcome if they are hospitalized in a stroke unit rather than in any other non-dedicated ward. Stroke unit care requires a multi-disciplinary team, involving expert medical, nursing and therapy staff, working closely together. Availability and fast access to diagnostic imaging and to laboratory testing 24 hours, and continuing education are also important components. Acute ischemic stroke patients can benefit from intravenous thrombolysis with t-PA. This drug must be administered within three hours of stroke onset following published inclusion and exclusion criteria. Intra-arterial thrombolysis is also an option, but the characteristics of the patients that can benefit from such a more aggressive approach are still to be defined. For a stable, consistent amelioration of stroke care, more funding for stroke research is needed. Despite similar clinical and economic 
burdens, the difference between the research funding available for stroke and that for heart disease and cancer is staggering. Funding for basic and clinical research focused on stroke has to be increased considerably, otherwise it will be arduous to develop and test new treatments to counteract the rising incidence of stroke.

\section{Nutrients and Gene Expression}

\author{
Raffaele De Caterina, Maria Annunziata Carluccio, \\ Marika Massaro \\ Chair of Cardiology, 'G. d'Annunzio' University, \\ Chieti; C.N.R. Institute of Clinical Physiology, Pisa, Italy
}

Besides providing feedback regulatory mechanisms controlling endogenous energy substrate availability in response to environmental changes, the type and abundance of nutrients may affect the organism's response to environmental challenges. Examples for this, originating from our own research, are the control of inflammatory and atherogenic responses to cytokines by omega-3 fatty acids and the monounsaturated fatty acid oleate. By partially replacing the corresponding omega- 6 and saturated analogues, respectively, omega-3 fatty acids and oleate have been shown to decrease the transcriptional activation of genes - e.g. adhesion molecules, chemoattractants, inflammatory genes and secondary cytokines - involved in endothelial activation in response to inflammatory and pro-atherogenic stimuli. This regulation occurs through a decreased activation of the nuclear factor (NF)- $\kappa \mathrm{B}$ system of transcription factors, secondary to decreased generation of intracellular hydrogen peroxides in conditions of membrane enrichment with unsaturated fatty acids. Such regulation by omega-3 fatty acids is likely linked to the presence of a higher number of double bonds accommodated in the same chain length in omega-3 as compared to omega- 6 fatty acids. This has consequences on the extent of leukocyte adhesion to vascular endothelium and the production of secondary mediators, ultimately controlling inflammation and atherogenesis. Other typical olive oil and red wine polyphenols affect endothelial adhesion molecule expression and monocyte adhesion. At nutritionally relevant concentrations, oleuropein, hydroxytyrosol and resveratrol, having marked antioxidant activity, reduce monocytoid cell adhesion, the expression of vascular cell adhesion molecule (VCAM)-1 protein and mRNA, and the activation of transcription factors NF- $\mathrm{KB}$ and activator protein (AP)-1.

Control of gene expression by unsaturated fatty acids and antioxidant polyphenols abundant in Mediterranean diets, being more and more unraveled in molecular details by the availability of modern molecular biology techniques, reveals our adaptation to environmental changes. Such understanding of body's physiology shed light on the origin of complex polygenic disease such as atherosclerosis and possibly some types of cancer. Together with two other recognized mechanisms of action, the substitution of the omega- 6 fatty acid arachidonic acid as a substrate for cyclooxygenases for the production of eicosanoids, and the control of ion currents in excitable tissues, regulation of gene expression promises to provide a comprehensive explanation of the health benefit of omega- 3 fatty acids. The understanding of the contributory effects of oleate and quantitatively minor polyphenols in quenching pro-atherogenic responses can now provide contributory explanations for the health effects of Mediterranean diets on atherosclerotic vascular disease.

\section{References}

Carluccio MA, Massaro M, Bonfrate C, Siculella L, Maffia M, Nicolardi G, Distante A, Storelli C, De Caterina R: Oleic acid inhibits endothelial activation - A direct vascular antiatherogenic mechanism of a nutritional component in the Mediterranean diet. Arterioscler Thromb Vasc Biol 1999;19(2):220-228.

Carluccio MA, Siculella L, Ancora MA, Massaro M, Scoditti E, Storelli C, Visioli F, Distante A, De Caterina R: Olive oil and red wine antioxidant polyphenols inhibit endothelial activation - antiatherogenic properties of Mediterranean diet phytochemicals. Arterioscler Thromb Vasc Biol 2003, in press.

De Caterina R: The regulation of expression of endothelial leukocyte adhesion molecules as a regulatory step in atherosclerosis and inflammation. Internal Medicine 1997;5:71-82.

De Caterina R: Dietary modulation of the inflammatory response. In Therapy in Nephrology and Hypertension, a companion to Brenner and Rector's The Kidney, HR Brady and CS Wilcox, WB Saunders Company, Philadelphia, 1999, Chapter 15, pp 96-103.

De Caterina R, Basta G: n-3 fatty acids and the inflammatory response biological background. Eur Heart J Suppl 2001;3(Suppl D):D42-D49.

De Caterina R, Bernini W, Carluccio MA, Liao JK, Libby P: Structural requirements for inhibition of cytokine-induced endothelial activation by unsaturated fatty acids. J Lipid Res 1998;39(5):1062-1070.

De Caterina R, Cybulsky MI, Clinton SK, Gimbrone MA Jr, Libby P: The omega-3 fatty acid docosahexaenoate reduces cytokine-induced expression of proatherogenic and proinflammatory proteins in human endothelial cells. Arterioscl Thromb 1994;14:1829-1836.

De Caterina R, Cybulsky MI, Clinton SK, Gimbrone MA Jr, Libby P: Omega-3 fatty acids and endothelial leukocyte adhesion molecules. Prostaglandins Leukotrienes and Essential Fatty Acids 1995;52:191-195.

De Caterina R, Liao JK, Libby P: Fatty acid modulation of endothelial activation. Am J Clin Nutr 2000;71(1S):213S-223S.

De Caterina R, Libby P: Control of endothelial leukocyte adhesion molecules by fatty acids. Lipids 1996;S31:S57-S63.

De Caterina R, Libby P, Peng H-B, Thannickal VJ, Rajavashisth TB, Gimbrone MA Jr, Shin WS, Liao JK: Nitric oxide decreases cytokine-induced endothelial activation. Nitric oxide selectively reduces endothelial expression of adhesion molecules and proinflammatory cytokines. J Clin Invest 1995;96:60-68.

De Caterina R, Spiecker M, Solaini G, Basta G, Bosetti F, Libby P, Liao J: The inhibition of endothelial activation by unsaturated fatty acids. Lipids 1999;34S:191S-194S

Ferrero ME, Bertelli AAE, Fulgenzi A, Pellegatta F, Corsi MM, Bonfrate M, Ferrara F, De Caterina R, Giovannini L, Bertelli A: Activity in vitro of resveratrol on granulocyte and monocyte adhesion to endothelium. Am J Clin Nutr 1998;68:1208-1214.

Massaro M, Basta G, Lazzerini G, Carluccio MA, Bosetti F, Solaini G, Tongiani R, Paolicchi A, De Caterina R: Quenching of intracellular ROS generation as a mechanism for oleate-induced reduction of endothelial activation and early atherogenesis. Thromb Haemost 2002;88:335-344.

Massaro M, Carluccio MA, Paolicchi A, Bosetti F, Solaini G, De Caterina R: Mechanisms for reduction of endothelial activation by oleate: Inhibition of nuclear factor-kappaB through antioxidant effects. Prostaglandins Leukot Essent Fatty Acids 2002;67:175-181.

Massaro M, De Caterina R: Effects of oleic acid on endothelial activation: A possible mechanism for prevention of atherosclerosis. Recent Research Development in Lipids 2001;5:85-96.

Massaro M, De Caterina R: Vasculoprotective effects of oleic acid: Epidemiological background and direct vascular antiatherogenic properties. Nutr Metab Cardiovasc Dis 2002;12:42-51. 


\section{Cardiovascular Risk Factors in 1,202 Families in Nürnberg (9. PEP - Survey)}

Peter Schwandt, Evelyn Liepold, Gerda-Maria Haas

Arteriosklerose - Präventions - Institut, München, Germany

The Prevention Education Program PEP is a 14 years prospective study starting with first class pupils and their families [1]. The aim is, to find out, whether early detection of cardiovascular risk factors and adapted life style modification on a family basis can change cardiovascular risk in Nuremberg, the Bavarian town with the highest prevalence of myocardial infarction death.

Here, we report about data from the 9 . survey. The table 1 partially summarises the CVD risk data from 4,197 individuals participating in this interim analyses (consisting - as every year - of the physical examination, the analyses of blood risk variables and the seven days dietary protocol).

Table 1 compares the data from all participants (0.1-89 years) with the data from the 6-10 years old children and the 19-50 years old men and women, who had at least one strong cardiovascular risk factor (as defined in the table 1): these were 738 males and 694 females.

In the children passive smoking is the most prominent risk factor (which had been substantiated in a subgroup by cotinine blood concentration determinations [2]), followed by $12 \%$ obesity - as has been already demonstrated previously [3]. Passive smoking is associated with pediatric dental caries with an estimated population attributable risk of up to $27 \%$ [4].

The highest risk was registered in the fathers: $26.1 \%$ smoking, $20.9 \%$ hypertension, $17.9 \%$ LDL-Cholesterol $\geq 155 \mathrm{mg} / \mathrm{dl}$. Interestingly, the mothers also had the highest risk (22.8\%) in the category smoking, which does explain the high prevalence of passive smoking in the children. The negative effect of smoking regarding the intake of antioxidants and vitamin plasma concentrations in this population has been shown previously [2]. At least one member from 865 families (out of the 1,202 families) had one severe cardiovascular risk factor.

Systolic blood pressure $\geq 115 \mathrm{~mm} \mathrm{Hg}$ accounts for $2 / 3$ of strokes and almost $1 / 2$ of CHD, and cholesterol concentrations $\geq 160 \mathrm{mg} / \mathrm{dl}$ for $18 \%$ and $55 \%$, respectively. The combination of personal and non-personal health interventions could lower the global incidence of cardiovascular events by as much as $50 \%$ [5].

\section{References}

1 Schwandt P, et al: The Prevention Education Program (PEP). A prospective study of the efficacy of family-oriented life style modification in the reduction of cardiovascular risk and disease: Design and baseline data. J Clin Epidemiol 1999;52(8):791-800.

2 Tröbs M, et al: Nutrition, antioxidants and risk factor profile of nonsmokers, passive smokers and smokers of the Prevention Education Program (PEP) in Nuremberg, Germany. Prev Med 2002;34(6):600-607.

3 Geiss HC, et al: Parameters of childhood obesity and their relationship to cardiovascular risk factors in healthy prepubescent children. Int J Obesity Relat Metab Disord 2001;25(6):830-837.

4 Aligne CA, et al: Association of pediatric dental caries with passive smoking. JAMA 2003;289:1258-1264.

5 Muray CJL, et al: Effectiveness and costs of intervention to lower systolic blood pressure and cholesterol: A global and regional analysis on reduction of cardiovascular disease risk. Lancet 2003;361:717-725.

\section{Risky Nutritional Habits in Italian Adolescents}

\section{Luca Scalfi, Mario Mancini}

Federico II University, Naples, Italy

Adolescence (10-19 years of age) is a life stage where the health behaviours, including eating behaviour and food habits in particular, are most vulnerable because of the dramatic biological, cognitive, and

Table 1: Cardiovascular risk factors in 4,197 PEP - participants (9. survey)

\begin{tabular}{|c|c|c|c|c|}
\hline Risk factors & Children $6-10$ years & Women $19-50$ years & Men 19-50 years & All participants \\
\hline Obesity & $\begin{array}{l}\mathrm{N}=1,043 \\
\geq 20 \% \text { reference weight } \\
\mathrm{N}=125(12.0 \%)\end{array}$ & $\begin{array}{l}\mathrm{N}=1,125 \\
\mathrm{BMI} \geq 30 \mathrm{~kg} / \mathrm{m}^{2} \\
\mathrm{~N}=108(9.6 \%)\end{array}$ & $\begin{array}{l}\mathrm{N}=760 \\
\mathrm{BMI} \geq 30 \mathrm{~kg} / \mathrm{m}^{2} \\
\mathrm{~N}=90(11.8 \%)\end{array}$ & $\begin{array}{l}\mathrm{N}=4,042 \\
\mathrm{BMI} \geq 30 \mathrm{~kg} / \mathrm{m}^{2} \\
\mathrm{~N}=459(11.4 \%)\end{array}$ \\
\hline High blood pressure $\mathrm{mm} / \mathrm{Hg}$ & $\begin{array}{l}N=1,040 \\
6-9 \text { years: } \geq 121 / 77 \\
10-12 \text { years: } \geq 125 / 81 \\
N=70(6.7 \%)\end{array}$ & $\begin{array}{l}\mathrm{N}=1,129 \\
\geq 140 / 90 \\
\mathrm{~N}=66(5.8 \%)\end{array}$ & $\begin{array}{l}N=759 \\
\geq 140 / 90 \\
N=159(20.9 \%)\end{array}$ & $\begin{array}{l}N=4,033 \\
\geq 140 / 90 \\
N=372(9.2 \%)\end{array}$ \\
\hline Triglycerides & $\begin{array}{l}\mathrm{N}=484 \\
\geq 129 \mathrm{mg} / \mathrm{dl} \\
\mathrm{N}=6(1.2 \%)\end{array}$ & $\begin{array}{l}\mathrm{N}=831 \\
\geq 250 \mathrm{mg} / \mathrm{dl} \\
\mathrm{N}=4(0.5 \%)\end{array}$ & $\begin{array}{l}\mathrm{N}=610 \\
\geq 250 \mathrm{mg} / \mathrm{dl} \\
\mathrm{N}=35(5.7 \%)\end{array}$ & $\begin{array}{l}\mathrm{N}=2,548 \\
\geq 250 \mathrm{mg} / \mathrm{dl} \\
\mathrm{N}=71(2.8 \%)\end{array}$ \\
\hline $\begin{array}{l}\text { HDL-Chol } \\
\leq 35 \mathrm{mg} / \mathrm{dl}\end{array}$ & $\begin{array}{l}\mathrm{N}=484 \\
\mathrm{~N}=21(4.3 \%)\end{array}$ & $\begin{array}{l}\mathrm{N}=831 \\
\mathrm{~N}=9(1.1 \%)\end{array}$ & $\begin{array}{l}\mathrm{N}=610 \\
\mathrm{~N}=63(5.7 \%)\end{array}$ & $\begin{array}{l}\mathrm{N}=2,548 \\
\mathrm{~N}=123(4.8 \%)\end{array}$ \\
\hline $\begin{array}{l}\text { Glucose } \\
\geq 126 \mathrm{mg} / \mathrm{dl}\end{array}$ & $\begin{array}{l}\mathrm{N}=487 \\
\mathrm{~N}=2(0.4 \%)\end{array}$ & $\begin{array}{l}\mathrm{N}=828 \\
\mathrm{~N}=11(1.3 \%)\end{array}$ & $\begin{array}{l}\mathrm{N}=610 \\
\mathrm{~N}=15(2.5 \%)\end{array}$ & $\begin{array}{l}\mathrm{N}=2,550 \\
\mathrm{~N}=46(1.8 \%)\end{array}$ \\
\hline
\end{tabular}


sociocultural changes occurring in this period. In particular, the food habits of adolescents and their evolution can be evaluated with respect to meal patterns, food choices, and intakes of energy and nutrients.

Firstly, meal patterns define number and timing of meals consumed during the day, with particular emphasis for breakfast and snacking. In many adolescents they are chaotic. Breakfast is frequently inadequate from the nutritional point of view and its energy content is less than desirable, with a significant percentage of individuals skipping this meal at all. Moreover, the low energy intakes at breakfast are probably compensated by increasing snacking. Not surprisingly, a number of studies have also demonstrated that breakfast consumption can be considered as a marker of appropriate intake of both energy and nutrients.

Snacking is common in adolescents, too; they eat more frequently between meals than the other age groups. The daily frequency of snacks seems to be higher in older adolescents than in the younger ones, while their number has probably been increasing in the last decades. Due to the fact that the nutritional characteristics of both savoury and sweet snacks is usually inadequate, snacking contribute to poor quality diets that are rich in total fat and saturated fat, and lacking in dietary fibre. Similarly eating outside the home, which is more common at weekends, is associated with the consumption of high energy density foods as confirmed by the positive relationship between fast food restaurant use and the intake of total energy and fat. Moreover, eating outside the home, may account for a considerable fraction of daily energy intake (up to $30-40 \%$ ).

Secondly, comparable trends in food choices are apparent in different industrialised countries, although some diversity still persists between USA, Northern Europe and Southern Europe. Indeed, the main finding of all studies is that the intake of vegetables and fruit is low, and sometimes very low. The consumption of milk and dairy products varies between countries, but many adolescents do not consume milk at all. In addition, adolescents eat too many meat and high-fat foods, while the consumption of junk foods (cheeseburger, French fries, etc) and soft drinks also is common and a cause of concern, as these products displace foods of better nutritional quality.

Thirdly, as consequence of the aforementioned food choices, adolescents often exhibit very unbalanced intakes of macro- and micronutrients. The consumption of fats (especially saturated fats) is high while that of complex carbohydrates and dietary fibre is low. The intakes of protein (mostly from animal origin) are well above recommendations and the same is true for sucrose. Salt intakes are expected to be excessive while, on the contrary, nutritional deficiencies can occur for calcium, iron and folic acid (the last two especially in females).

The dietary lifestyle of adolescents depend on individual influences, social environmental influences, physical environmental influences and macrosystem influences. In particular, food habits are expected to vary among the industrialised countries first of all because of various combinations of sociocultural factors. Indeed, between-nation comparisons are difficult because the studies on this topic widely differ with respect to experimental protocols, methods, age of subjects, etc. Furthermore, dietary habits are supposed to have been changing quite rapidly in the last years, making more difficult to consider as up to date even the data that were published 10-15 years ago.

Indeed, if Southern Europe is taken into consideration, what really persists of the healthy nutritional style named 'Mediterranean diet' in the food habits of the adolescents living in those countries?

International Conference on Genetic

Variation, Nutrition and Physical Activity
A limited amount of data is available on this issue. According to some studies, snacking is less frequent in Southern European countries as well as skipping breakfast. Some characteristics of the Mediterranean diet still persist, such as a relatively higher consumption of olive oil and a relatively higher intake of vegetables and fruits. On the other hand, the consumption of foods from animal sources and that of confectionery, cakes, biscuits, etc is increasing. Fat intakes are high, and the same is true for protein intake.

We have recently performed some studies on 17-19 years old adolescents living in the Neapolitan area. The results we obtained confirm the idea of a trend toward a Westernised Mediterranean Diet. For instance, a significant percentage of subjects did not eat at all vegetables and fruits. A shift was apparent from starchy foods such as pasta and bread, to sugar-rich foods, while the consumption of meat, salami and cold pork meats, and junk foods was frequent.

Thus, the deterioration of nutritional lifestyles that is common in industrialised countries, and also in Southern Europe countries, puts adolescents at risk for both immediate consequences (obesity, hyperlipidemia, diabetes) and long-term consequences (cardiovascular disease, cancer, and osteoporosis). The improvement of food habits of adolescents represents an important and mandatory goal for public health interventions in the general population.

\section{Nutrition and CVD Risk Factors in Crete, Greece}

\section{Anthony Kafatos, Joanna Moschandreas \\ University of Crete School of Medicine, Crete, Greece}

Cardiovascular diseases are the major causes of death in Europe [1]. Greece is a country renowned for its low CVD morbidity and mortality rates. In recent years, however, there has been an increase in the prevalence of factors known to influence the risk of CVD, such as obesity, high blood pressure, elevated cholesterol levels and behavioural risk factors. Also, trends in mortality CVD levels in Greece over the past few decades are unfavourable compared to those of other European countries. Diet is known to strongly influence levels of CVD risk factors and the interaction between diet and many other CVD risk factors depends on age. The aim here is to present changes in dietary habits and associated changes in CVD risk factors and mortality over the last few decades in Greece using data from recent studies in different age groups.

Knowledge of the health benefits of the Greek, and in particular the Cretan, diet have been derived from various epidemiological studies, including the data arising from the Seven Countries Study (SCS) [2]. One of the 16 SCS cohorts consisted of 686 rural central Cretan men initially examined in 1960 . The vital status and dietary habits of the cohort have been followed up for 40 years and $23 \%$ of the Cretan men were alive forty years later. The corresponding percentage in the other Greek SCS cohort, from Corfu, was only $13 \%$. Significant baseline prognostic factors were age, blood pressure, serum cholesterol concentration, vital capacity, forced expiratory volume (FEV) and smoking status. The hazard of death for smokers in 1960, accounting for other prognostic factors, was $49 \%$ higher than for those who had never smoked (95\% confidence interval $18 \%$ to $86 \%$ ). There were $228 \mathrm{CVD}$ deaths (33\%); age at entry, systolic blood pressure, vital capacity and FEV were found to be significant 
predictors with relative risks very similar to those for the all-cause end-point.

Data of the 153 men who agreed to be re-examined in 2000 (91\% of the survivors), men with mean age $85 \mathrm{yrs}$ (SD $4 \mathrm{yrs}$ ), indicate that the dietary pattern of these elderly rural men has changed in that there is now higher average consumption of both fish and meat than at baseline (meat intake $46 \%$ higher, fish intake 56\% higher), although the percentage of energy derived from saturated fat remains significantly lower than that for the men comprising the Zutphen Elderly Study cohort (11.4, SD 2.0, \%En c.f. 14.3, SD 2.9, \%En, p < 0.0001). The mean level of serum folate was significantly higher in men from Crete $(6.42 \mathrm{ng} / \mathrm{ml})$ than Zutphen $(4.80 \mathrm{ng} / \mathrm{ml})(\mathrm{p}<0.001)$, whereas vitamin B12 levels were lower $(355 \mathrm{pg} / \mathrm{ml}$ and $432 \mathrm{pg} / \mathrm{ml}$, respectively, $\mathrm{p}<0.001)$. These differences may be due to the higher vegetable and fruit consumption in Crete and the higher consumption of meat and dairy products in Zutphen. The mean concentration of serum hydroperoxides was significantly lower in men from Crete $(34.2 \mu \mathrm{mol} / \mathrm{L})$ compared to men from Zutphen $(55.4 \mu \mathrm{mol} / \mathrm{L})$ $(\mathrm{p}<0.01)$. Also, men from Crete had lower serum ferritin $(65 \mu \mathrm{mol} / \mathrm{L}$ and $137 \mu \mathrm{mol} / \mathrm{L}$, respectively) and iron levels $(15.0 \mu \mathrm{mol} / \mathrm{L}$ and $17.7 \mu \mathrm{mol} / \mathrm{L}$, respectively) (both $\mathrm{p}<0.001$ ). In middle-aged Greek men today, prevalence of CHD risk factors has been found to be higher than in the Cretan SCS men in the early 1960s. For example, only $2 \%$ of the latter were obese (BMI $>30 \mathrm{~kg} / \mathrm{m}^{2}$ ).

The prevalence of CHD risk factors may be even higher in young adults. The health and nutritional status of 951 third-year Greek medical students (53\% male) was evaluated from 1989 to 2001 . Thirty two percent of males and $30 \%$ of females were current smokers [3]. Overweight/obesity levels were at $39 \%$ in males and $23 \%$ in females; obesity status was related to the presence of hypertension (13\% males and $7 \%$ females had blood pressure $>140 / 90 \mathrm{mmHg}$ ) and dyslipidemia ( $14 \%$ males and $5 \%$ females had HDL-cholesterol $<35 \mathrm{mg} / \mathrm{dL}$ ) [4].

Similar discouraging CVD risk factor levels are found in the population of children of Crete. In 2000, a study of the 200 children attending nursery, primary or secondary school in a mountainous region of Crete, the supposedly traditional village of Rouvas, indicated that, using International Obesity Task Force (IOTF) sex- and half-year specific cut-offs for BMI [5], the overall prevalence of overweight/obesity was $33 \%$. Other CVD risk factors were also found to be at high levels. More encouraging results were those of a six-year health and nutrition education intervention programme undertaken in all primary schools in three of the four counties of Crete between 1992 and 1998 (about 6,000 children). Results from a random sample of 40 Cretan primary schools $(1,046$ pupils) indicated that biochemical indices improved to a greater extent in the intervention group than in the controls whilst total energy intake and total energy and saturated fat intake increased significantly less in the intervention group compared to the controls (mean increases $179 \mathrm{kcal} / \mathrm{d}$ c.f. $367 \mathrm{kcal} / \mathrm{d}$ and $0.8 \mathrm{~g} / \mathrm{d}$ c.f $5.1 \mathrm{~g} / \mathrm{d}$ ). In addition, both the time devoted to physical activity and the cardiovascular run test performance increased to a greater extent in the intervention group [6]. All subjects who participated in the 1998 follow-up were invited for examination three years later. The overall percentages of pupils overweight or obese using IOTF criteria were $23 \%$ of first grade pupils and $35 \%$ by the time these pupils had reached 6th grade. Of the 9 th grade pupils, $32 \%$ were overweight or obese. Preliminary results indicate that the positive effects of the intervention programme continue into adolescence.

It is not clear that reaching single recommended cut-off levels for CVD risk factors would reduce the risk to the same extent in all countries in Europe. It has been reported that prevention and treatment of a certain serum cholesterol or blood pressure measurement has a greater health effect in Northern Europe compared to Southern Europe [1]. For example, at a given cholesterol level of $200 \mathrm{mg} / \mathrm{dL}$, the absolute risk for long-term CHD is 5 times higher for Northern Europe than for Mediterranean Southern Europe [1]. It will be interesting in further research to examine the possible effects of genetic predisposition to CVD.

\section{References}

1 Kromhout D: Epidemiology of cardiovascular diseases in Europe. Public Health Nutr 2001;4(2B):441-457.

2 Menotti A, Kromhout D, Blackburn H, Fidanza F, Buzina R, Nissinen A: Food intake patterns and 25-year mortality from coronary heart disease: Cross-cultural correlations in the Seven Countries Study. The Seven Countries Study Research Group. Eur J Epidemiol 1999;15(6):507-515.

3 Mammas I, Bertsias G, Linardakis M, Moschandreas J, Kafatos A: Dietary intake of Greek medical students assessed during a Clinical Nutrition course. Int J Vit Nutr Res 2003, in press.

4 Bertsias G, Mammas I, Linardakis M, Kafatos A: Overweight and obesity in relation to cardiovascular disease risk factors among medical students in Crete, Greece. BMC Public Health 2003;3(1):3.

5 Cole TJ, Bellizzi MC, Flegal KM, Dietz WH: Stablishing a standard definition for child overweight and obesity worldwide: International survey. BMJ 2000;320(7244):1240-1243.

6 Manios Y, Moschandreas J, Hatzis C, Kafatos A: Health and nutrition education in primary schools of Crete: Changes in chronic disease risk factors following a 6-year intervention programme. Br J Nutr 2002; 88(3):315-324.

\section{Gene-Environment Interaction in Coronary Artery Disease: Smoking and Apolipoprotein E and Interleukin-6 as Examples}

\author{
Steve E. Humphries', Dave Brull', Le A. Luong ${ }^{1}$, \\ Emma Hawe ${ }^{1}$, George J. Miller ${ }^{2}$, Philippa J. Talmud ${ }^{1}$ \\ ${ }^{1}$ Royal Free and University College London Medical \\ School; ${ }^{2}$ MRC Epidemiology and Medical Care Unit, \\ Wolfson Institute of Preventive Medicine, \\ St. Bartholomew's Hospital, London, UK
}

\section{Background}

In understanding the development of CAD, the modifying effects of environmental factors on an individual's genotype is particularly important. Of the environmental factors, smoking makes a major contribution, both by causing inflammation and damage to lung and vascular endothelium, leading to increased secretion of adhesion molecules which promotes thrombosis and atherosclerosis, and by disturbing lipoprotein metabolism and increasing the production of small dense LDL. The common isoforms of apoE (E2, E3, E4) are important determinants of plasma lipid levels and the E4 allele is associated with risk of CHD. We have therefore examined whether the impact of smoking on CAD risk is influenced by $A P O E$ genotype [1].

\section{ApoE Genotype: Smoking Interaction}

The interaction of apoE and smoking on CHD risk was examined in the UK-based Northwick Park Heart Study. Subjects were middleaged men, free of CAD at baseline. APOE genotype was associated with the expected effects on plasma cholesterol and apoB levels 
(both $\mathrm{p}<0.0001$ ). During 18,836 person years of surveillance of 2,258 men, 136 CHD events had occurred. The effect of smoking alone on CHD risk was 1.94 (95\% CI 1.25-3.01) in agreement with previous studies which find smoking to double CHD risk. Compared to all genotype never smokers, where the hazard ratio was set at 1.00, in men who smoked, those with the genotype $\varepsilon 3 / \varepsilon 3$, had a hazard ratio was 1.68 (95\% CI 1.01-2.83) compared to 1.18 (95\% CI $0.46-3.03$ ) for $\varepsilon 2$ carriers and 3.17 (95\% CI 1.82-5.51) in $\varepsilon 4$ carriers. The interaction between smoking status and $A P O E$ genotype on CHD risk was significant $(\mathrm{p}=0.007)$. Interestingly, in the non-smokers carrying the E4 allele risk was $0.84(0.40-1.75)$, supporting the benefit in CAD risk reduction of smoking cessation.

In these men the increased risk associated with smoking and carrying an $\varepsilon 4$ allele was independent of BMI, blood pressure, lipid levels and markers of inflammation. Thus although the mechanisms for these cholesterol-independent effects on arterial wall thickening are unclear, it appears that $A P O E$ genotype influences CAD independently of its effects on fasting plasma lipid levels. The interaction of $\varepsilon 4$ and smoking suggests that smoking exacerbates this. The most likely mechanism to explain the $\varepsilon 4$ :smoking interaction on CHD risk appears to be through a direct effect on LDL oxidation. Several studies using recombinant apoE have demonstrated that the protection against oxidation in vitro is E2 $>\mathrm{E} 3>\mathrm{E} 4$, due probably to the fact that E2 has two free SH-groups, E3 has one and E4 none. The differential oxidation of apoE isoforms has now been confirmed in vitro with, as expected, E4 being more susceptible than E3 which in turn is more susceptible than E2, to oxidation [2].

Inflammation is a key component of $\mathrm{CAD}$, and genes coding for cytokines are candidates for predisposing to atherosclerosis. In the IL- 6 promoter we have detected a $\mathrm{G}>\mathrm{C}$ change at -174 (freq $\mathrm{C}=0.41$ ), and shown this change to be functional in vitro [3]. We have shown that (independently of classical risk factors) the $-174 \mathrm{C}$ allele is associated with 1.8 fold higher CAD mortality in patients with Abdominal Aortic Aneurysms [4]. In the NPHS study [5], compared to those with the genotype GG, men carrying the $-174 \mathrm{C}$ allele had a relative risk of CAD of 1.54 (95\% CI 1.0-2.23) and this effect was greatest in smokers (compared to GG non-smokers, RR 2.66, CI 1.64-4.32), and remained statistically significant after adjusting for classical risk factors $(p=0.04)$. In patients undergoing coronary artery bypass graft surgery (CABG) IL-6 levels 6 hours post CABG, were $26 \%$ higher in those with the genotype $-174 \mathrm{CC}$, compared to $-174 \mathrm{G}$ carriers $(\mathrm{p}=0.04)$ [6], confirming that this polymorphism is functional in vivo, particularly after acute severe injury.

In conclusion, smoking was associated with increased risk of CAD in men of all APOE and IL-6 genotypes but this was particularly marked in E4 and IL-6 - 176C carriers, and independent of effects of genotype on levels of classical risk factors. These data confirm the importance of the inflammatory system in the development of CAD, although the molecular mechanisms whereby these genetically determined differences effect risk remain to be determined. Men who carry the E4 allele represent $26 \%$, and those carrying the $-174 \mathrm{C}$ allele $48 \%$ of the population, and their high risk of CAD when a smoker provides a strong and individually-targeted argument for smoking cessation.

\section{Future Work}

Concern has been raised about the apparent 'inconsistency' of genetic association studies, with genotypes being associated with large effects on CHD risk in the initial published report, but with subsequent (larger) studies failing to confirm this effect, or at best finding an effect of much more modest size. This problem is amenable to meta-analysis and such an analysis of 36 associations in CAD, diabetes, hypertension, cancer, etc, was recently published [7]. The overall message of this paper is extremely encouraging; namely that many of the reported associations between certain genotypes and disease risk do stand up to the test of replication, albeit with the estimated risk lower than that originally reported. The same sort of rules must be applied to the gene:environment interactions discussed above. It is worth publishing such interactions providing they are carried out on a reasonably sized sample, because they will stimulate workers in the field to try to replicate the observation.

This work was funded by the British Heart Foundation.

\section{References}

1 Humphries SE, Talmud PJ, Hawe E, Bolla M, Day IN, Miller GJ: Apolipoprotein E4 and coronary heart disease in middle-aged men who smoke: A prospective study. Lancet 2001;358:115-119.

2 Jolivalt C, Leininger-Muller B, Bertrand P, Herber R, Christen Y, Siest G: Differential oxidation of apolipoprotein $\mathrm{E}$ isoforms and interaction with phospholipids. Free Radic Biol Med 2000;28:129-140.

3 Fishman D, Faulds G, Jeffery R, Mohamed-Ali V, Yudkin JS, Humphries S, Woo P: The effect of novel polymorphisms in the interleukin-6 (IL-6) gene on IL-6 transcription, plasma IL-6 levels, an association with systemic onset juvenile chronic arthritis. Journal of Clinical Investigation 1998;102(7):1369-1376.

4 Jones KG, Brull DJ, Brown LC, Sian M, Greenhalgh RM, Humphries SE, Powell JT: Interleukin-6, (IL-6) and the prognosis of abdominal aortic aneurysms. Circulation 2001;103:2260-2265.

5 Humphries SE, Luong L-A, Ogg MS, Hawe E, Miller G: The interleukin-6 $-174 \mathrm{C}>\mathrm{G}$ promoter polymorphism is associated with risk of coronary artery disease and systolic blood pressure in healthy men. European Heart Journal 2001;22:2243-2252.

6 Brull D, Montgomery HE, Sanders J, Dhamrait S, Luong L-A, Rumley A, Lowe GDO, Humphries SE: Interleukin-6 gene $-174 \mathrm{G}>\mathrm{C}$ and $-152 \mathrm{G}>\mathrm{C}$ polymorphisms are strong predictors of plasma IL6 levels after cardiopulmonary bypass. Arteriosclerosis, Thrombosis, and Vascular Biology 2001;21:1458-1463.

7 Ioannidis JP, Ntzani EE, Trikalinos TA, Contopoulos-Ioannidis DG: Replication validity of genetic association studies. Nat Genet 2001;29: 306-309.

\section{Vitamin Metabolism, Genetics, and the Environment}

\author{
Antonio Velázquez, Cristina Fernandez-Mejia \\ Unidad de Genética de la Nutrición, Instituto de \\ Investigaciones Biomédicas de la Universidad Nacional \\ Autónoma de México, e Instituto Nacional de Pediatría, \\ México
}

In mammals, including humans, vitamins are metabolized to a limited extent. With some exceptions (vitamins C and D) they are not synthesized and are essential nutrients. They function as coenzymes or as hormones and, in one case (vitamin D) as both. Some need to be converted into their functional forms after intake. When acting as coenzymes they usually associate tightly with their respective apoenzymes, which then become active holoenzymes. Often, these associations are established by enzyme-catalyzed covalent bonds, which may be broken by specific enzymes during holoenzyme turnover. 
Most coenzymes are reversibly transformed between the coenzymatically active form and inactive form(s).

Recently, a new role for vitamins is being documented, as regulators of genetic expression. Directly or, most likely, through signaling pathways, an increasing number of vitamin-mediated effects are being discovered at the level of transcription and/or translation.

Therefore, a significant portion of the genome codes for these multiple, interrelated functions that directly or indirectly participate in the metabolism of vitamins. Global approaches (microarrays, SAGE, etc) are essential for exploring these complex networks. However, these kind of approaches are novel, fraught with standardization and quality control difficulties, and for results interpretation require quite elaborate bioinformatic tools which are still being developed. In particular, we have not been able to find published reports of this type of studies performed on vitamin metabolism. Therefore, the rest of our presentation we will deal with studies perused by more conventional means on the metabolism - and on some metabolic effects - of two different vitamins - vitamin A and biotin - on which we have been working. The purpose will be to show the range of interrelated metabolic steps that would be greatly clarified with global (genomic, proteomic, etc) perspectives.

\section{Vitamin A}

Vitamin A is an essential precursor of tissue retinol, which is metabolized by sequential reactions into two classes of biologically active retinoids. The 11-cis-retinoids function specifically in vision, whereas the acidic retinoids, all-trans-retinoic acid and 9-cis-retinoic acid, are regulators of many systemic processes via their capacity to activate two families of nuclear receptors. The best-known function of vitamin $\mathrm{A}$ is in the visual process where, in the form of 11-cisretinal, it serves as the photosensitive chromophoric group of the visual pigments of rod and cone cells of the retina. The best recognized systemic functions of vitamin A involve roles in morphogenesis, immunity, growth and epithelial cell differentiation. The master key role of retinoids on these functions has favored the development of new therapeutics in dermatological and cancer treatment. Other effects of vitamin A are on carbohydrate metabolism. Our group has contributed to the understanding of the molecular basis of vitamin A on glucose metabolism. We found that retinoic acid regulates the expression of critical proteins in carbohydrate metabolism: insulin and glucokinase. This latter enzyme plays a key-role in glucose homeostasis, regulating insulin secretion in response to glucose in the pancreatic beta cells and uptake of glucose in the liver. Our studies demonstrated that retinoic acid increases pancreatic and hepatic glucokinase activity and mRNA levels, these effects being independent of the differentiating action of retinoic acid. The retinoid achieves its effects on pancreatic glucokinase, at least in part, through the stimulation of the beta-cell glucokinase promoter. We also found that retinoic acid increases glucose-induced insulin secretion. These effects of retinoic acid on glucose metabolism provide an intellectual basis for the development of novel pharmacological regulators of glucose metabolism that act through their effects on glucokinase and insulin expression.

\section{Biotin}

Biotin is the cofactor of carboxylases (pyruvate, propionyl-CoA, 3-methyl crotonyl-CoA and acetyl-CoA), to which it is covalently bound by the action of holocarboxylase synthetase (HCS). It also affects genetic expression. The carboxylases participate in the metabolism of carbohydrates, lipids and proteins, catalyzing the carboxylation of different metabolites. They are synthesized as inactive apocarboxylases. HCS catalyzes their activation by covalently binding biotin to a lysine residue. We found that in intact rats this vitamin regulates the genetic expression of the enzymes to which it is functionally related, at the mRNA level in the case of HCS and at the protein levels of carboxylases. These effects were observed in different organs, but not in the brain of the biotin-deficient rats, suggesting that this organ is protected to some extent during the vitamin deficiency. Results will also be presented on the expression of the multivitamin transporter (SMVT). At our institute, Alfonso León-del-Río, working on transformed human cultured cell lines, has extended these studies demonstrating that the regulatory role of biotin is likely through a signaling cascade that requires HCS, guanylate cyclase and cGMP-dependent protein kinase, mediated by biotinyl-5'-AMP.

Besides its role as cofactor of carboxylases, we and others have shown that biotin participates in the regulation of carbohydrate metabolism and of blood glucose levels, in particular on glucokinase, phosphoenolpyruvate carboxykinase and insulin, and on the receptors of asialoglycoprotein and of insulin. Some of these effects seem to be mediated by changes in cGMP levels resulting from stimulation of guanylate cyclase.

Therefore, to sustain their functions, vitamins require to be metabolized, something which involves digestion, absorption, blood transport, uptake and storage, intraorgan trafficking, biologic transformation to their active products, and excretion. Their understanding in a coherent fashion is an important challenge. Fortunately we have now the concepts and tools to tackle it.

\section{Nutrigenomics: Ethical and Social Responsibility}

\section{Lynn Frewer}

\section{University of Wageningen, Marketing and Consumer Behaviour Group, Wageningen, The Netherlands}

There is an assumption prevalent within the current natural science research that people will be more accepting of novel foods if there is a concrete and tangible consumer benefit associated with different products. This conclusion has largely been the result of consumer negativity associated with genetically modified foods - which has been attributed to the lack of tangible consumer benefits associated with the first products entering the market place. It has also been assumed that consumers will respond in an homogenous way to product innovations, despite variation in the value systems, which determine people's reactions. For example, some individuals have high levels of environmental concern associated with production processes such as genetic modification. Others have moral concerns relating to the application of human genetics, or object to the increasing globalisation of world trade. Values such as these are likely to play an important part in determining the acceptability of nutrigenomics and its applications. In addition, factors such as individual health status, and people's perceptions of their health status, are likely to influence people's acceptance of products targeted at specific health issues.

With any emerging technology applied to food production, various key questions should be asked. These include the following:

- What is driving consumer perceptions of risk and benefit?

- Who trusts whom to inform and regulate? How does this relate to consumer confidence in the food chain and associated science base? 
- Are there cross-cultural and intra-individual differences in perceptions and information needs?

- How might the wider public be involved in the debate about risk management and technological development?

- How do related factors (ethics, wider value systems) relate to perceptions of risk?

- How does the public react to information about risk uncertainty?

In the area of nutrigenomics, there has been little systematic research into the determinants of consumer acceptance. Some individual differences have emerged. There are also differences in terms of food innovation processes. Furthermore, various barriers to healthy eating that have already been identified are also likely to have a negative impact on consumer acceptance of nutriceuticals. People are reluctant to make dietary changes that may result in long-term prevention of ill health, or even improve their current health status, if they are considering health risks that may occur in the future. People also tend to exhibit 'optimistic bias' regarding their own health risks. Optimistic bias occurs when people perceive that they are at less risk from a particular hazard than other people, although it is possible to reduce such biases through manipulation of information interventions. Whether such interventions are regarded as ethical may be open to debate.

There are also societal issues, which may play a very important part in determining the acceptability or otherwise of novel nutrigenomics applications. These include problems specifically linked to human genetics research. For example, the issue of genetic privacy is becoming more important. The question people may ask is to what extent should human genetic databases be anonymised? There is increased concern about personal economic consequences of genetics research. For instance, will people who are identified as being 'at risk' from particular diseases be uninsurable, unemployable and unable to raise the finance to buy property. Individuals who lack a genetic predisposition to develop a disease may use this genetic information to reinforce 'optimistic biases' about their risks through environmental exposure or food choices. Finally, people who do have a genetic predisposition may develop a fatalistic response - if they believe that they are genetically predetermined to experience the illness, they may not attempt prevention through nutritional means. Research also indicates that people are more positive about nutriceutical products that have a positive impact on affective disorders compared to other illnesses and diseases. The latter appear more amenable to traditional medical interventions as far as public perceptions are concerned, at least in the present time.
The development of nutriceuticals targeted towards individuals with particular genetic predispositions has highlighted the need to develop individuated approaches to information delivery that will overcome the various barriers to dietary change. It is also important that the process of technology innovation takes due account of associated public concerns, including ethical issues which may arise. Effective public consultation during technology implementation will become increasingly important. All of the above represents important foci for social research in the short to medium term. However, it is essential that transdisciplinary research programmes (integrating both social and natural sciences in the development of the science itself and associated consumer products) ensure that technological advances take account of public concerns and preferences regarding technology development.

The emerging 'science and society' agenda identifies the need to change institutional terms of reference and procedures, including the development of a broader base of public consultation and dialogue on risk issues.

There are a variety of practical and ethical reasons for policymaking bodies to involve lay people in decision making on issues in which the public has a stake. Political theorists and ethicists discuss concepts such as democracy, procedural justice, and human rights, in providing the moral basis for involvement; but it is now recognised that, in a practical and expedient sense, making decisions without public support is liable to lead to confrontation, dispute, disruption, boycott, unrest, distrust, and public dissatisfaction in science and technology. This need for public involvement would seem particularly evident in the food domain, as the food we eat is of fundamental, unavoidable and everyday interest to all members of society. A plethora of different consultation processes have been developed. However, it is important to systematically evaluate whether consultation processes are effective, whether the outputs inform policy decision-making, and whether public consultation has a substantial impact on public confidence in science and technology. Failure to do so may result in technology innovation processes being the catalysts for further public distrust in science, regulatory institutions and the food industry.

In conclusion, it is essential that the public be involved as full partners in the process of technology implementation and innovation. Ultimately, only through systematic understanding of the public's needs and concerns will the emerging science of nutrigenomics result in the successful commercialisation of useful and beneficial consumer products, targeted at consumer preferences for technology implementation. 


\section{Annals of Nutrition\& Metabolism}

Baule, G.M. 240

Brull, D. 250

Cao, A. 245

Capurso, A. 243

Capurso, C. 243

Carluccio, M.A. 247

Colacicco, A.M. 243

Congia, M. 245

Cucca, F. 238

De Caterina, R. 247

de Lorgeril, M. 231

D'Introno, A. 243

Farchi, G. 244
Fernandez-Mejia, C. 251

Ferrari, S. 233

Fieschi, C. 246

Frewer, L. 252

Haas, G-M. 248

Hawe, E. 250

Humphries, S.E. 250

Iacoviello, L. 231

Kafatos, A. 249

Liepold, E. 248

Luong, L.A. 250
Mancini, M. 248

Massaro, M. 247

Miller, G.J. 250

Molloy, A.M. 234

Montgomery, H. 231

Moschandreas, J. 249

Muntoni, S. 238, 241

Muntoni, Sa. 239

Nestel, P. 233

Ordovas, J.M. 237

Panza, F. 243

Payne, J. 231
Reaven, G. 242

Scalfi, L. 248

Schwandt, P. 248

Simopoulos, A.P. 230

Solfrizzi, V. 243

Talmud, P.J. 236, 250

Torres, F. 243

Velázquez, A. 251

\section{KARGER}

(C) 2003 S. Karger AG, Basel

Fax +4161306 1234

E-Mail karger@karger.ch

www.karger.com

Accessible online at: www.karger.com/anm 